\title{
Experimental study on ferritic stainless steel RHS and SHS cross-sectional resistance under combined loading
}

\author{
I. Arrayago*, E. Real
}

Department of Civil and Environmental Engineering, Universitat Politècnica de Catalunya, Jordi Girona 1-3, Barcelona 08034, Spain

*Corresponding author: Tel: +34 934054156; Fax: +34 934054135, e-mail:

itsaso.arrayago@upc.edu

\section{Abstract}

The excellent corrosion resistance presented by all stainless steel grades, together with their appropriate mechanical properties, aesthetic appearance and easy maintenance, makes these metallic alloys perfect for sustainable structural performances. However, their nonlinear stressstrain behaviour together with their strong strain hardening features, makes them different from carbon steel and makes the development of some specific guidance necessary. Although the compressive and flexural behaviour of stainless steel Rectangular and Square Hollow Sections (RHS and SHS) has been widely analysed and advanced design approaches considering strain hardening have been developed, more general loading conditions such as combined axial compression and bending moment loading conditions still need to be investigated. Within this scenario, this paper presents an experimental programme on several ferritic RHS and SHS stub column tests subjected to concentric and eccentric compression. The objective is to extend the recent research on austenitic and lean duplex stainless steel RHS under combined loading to ferritic grades by assessing the applicability and accuracy of the interaction expressions currently codified in EN1993-1-4 and those proposed in the literature.

\section{Highlights}

- Compression stub column tests on ferritic stainless steel RHS and SHS are presented

- Combined loading stub column tests on ferritic stainless steel RHS and SHS

- Design methods for cross-sectional resistance under pure compression are assessed 
- Class 3 limits for internal elements in compression are analyzed

- Different interaction expressions for combined loading are assessed

\section{Keywords}

Experimental programme, Ferritic stainless steel, Cold-formed, Combined-loading, Continuous Strength Method, Stub column

\section{Introduction}

The use of stainless steel structural elements in construction has been increasingly spreading in the last years as a result of its excellent corrosion resistance, easy maintenance, good mechanical properties and aesthetic appearance. However, stainless steel alloys need a high initial investment, as they are strongly alloyed materials, containing high quantities of chromium, nickel, etc. The stainless steel grades most commonly utilized in construction are austenitic grades, which are also those characterized by the highest initial investment requirements. Stainless steel producers have been working hard on the development of new grades with lower associated material costs maintaining the rest of desirable properties. Ferritic stainless steels, with lower nickel content are, therefore, cheaper and relatively more pricestable than the most usual austenitic grades but still maintaining a significant part of their corrosion resistance, good ductility, formability and impact resistance as established in Baddoo and Cashell [1].

Besides, all stainless steel grades are characterized by a nonlinear stress-strain behaviour, making the development of some special features in the extension of the design rules for carbon steel to stainless steels in EN1993-1-4 [2] necessary, and strain hardening effects can be considerable for austenitic and duplex stainless steel grades, but more limited for ferritics. In addition, design expressions based on a discrete cross-sectional classification without having 
strain hardening effects into consideration usually provide overconservative predictions, being one of the drawbacks for the extension of stainless steels due to their higher initial investment needs when they are considered for structural design. Therefore, the development of specific and efficient guidance is key for the expansion of this material.

During the last few years a new design approach, based on cross-sectional deformation capacity and considering a more realistic stress-strain behaviour of the materials, has been developed: the Continuous Strength Method (CSM), whose applicability to stainless steel cross-sections was assessed by Afshan and Gardner [3].

The response of stainless steel cross-sections to isolated axial compression and bending moment loading conditions has been widely investigated for both the expressions codified in EN1993-1-4 [2] and those proposed in [3]. However, few investigations on combined axial compression and bending moment loading conditions are available nowadays. The extension of the CSM to more general loading conditions, such as combined loading, still needs to be deeply analysed. Recent numerical analysis on ferritic RHS and SHS subjected to combined loading was carried out by Arrayago et al. [4] and some experimental tests were published by Zhao et al. for austenitic, lean duplex [5,6] and ferritic [7] RHS and SHS under combined loading. Both investigations led to very similar conclusions, where the use of the interaction expression codified in [2] but considering axial and flexural cross-sectional capacities according to the CSM was found to be the most appropriate design approach, providing accurate previsions while maintaining design prescriptions as similar as possible to those codified for carbon steel in order to facilitate the design of stainless steel structures.

In order to complete these research works, an experimental programme on ferritic stainless steel RHS and SHS is presented in this paper, to determine the cross-sectional resistance under combined loading. Material properties were determined by conducting several tensile tests on 
flat and corner coupons extracted from cold-formed cross-sections, so as to correctly analyse the experimental results. Tests on five different cross-sections (three RHS and two SHS) are described, both under pure compression and under combined compression and bending moment conditions.

\section{Experimental tests}

\subsection{Introduction}

An experimental programme on ferritic stainless steel hollow sections has been conducted in order to investigate the behaviour of these types of cross-sections to different loading conditions. The tests presented in this paper consisted of a series of stub column tests subjected to compression and several tests on stub columns under combined compression and uniaxial bending moment loading conditions. Five different cross-sections have been analysed and presented in this paper: three Rectangular Hollow Sections (RHS) and two Square Hollow Sections (SHS). Cross-sections have been labelled as follows along the paper: S1-80x80x4, S260x60x3, S3-80x40x4, S4-120x80x3 and S5-70x50x2 and all the tested specimens were made from ferritic stainless steel grade EN1.4003 and were cold-rolled and seam welded.

\subsection{Material and initial imperfection characterization}

The determination of the actual mechanical behaviour of the material is key for the correct interpretation of the experimental data. Hence, several coupons were extracted from some specimens with the same cross-sections analysed in this paper. For each cross-section four coupons were extracted and machined, two from the flat parts of the cross-section (labelled as F) and two from the corner parts (labelled as C), having tested a total of 20 coupons. The location of the coupons in the cross-section is presented in Figure 1, together with the definition of the most important cross-section geometrical symbols. Tensile tests were conducted on these coupons to determine the stress-strain behaviour of the different parts of the cross-sections, 
which is generally different for those specimens extracted from the flat or corner regions of the cross-section, due to the effect of cold-forming processes.

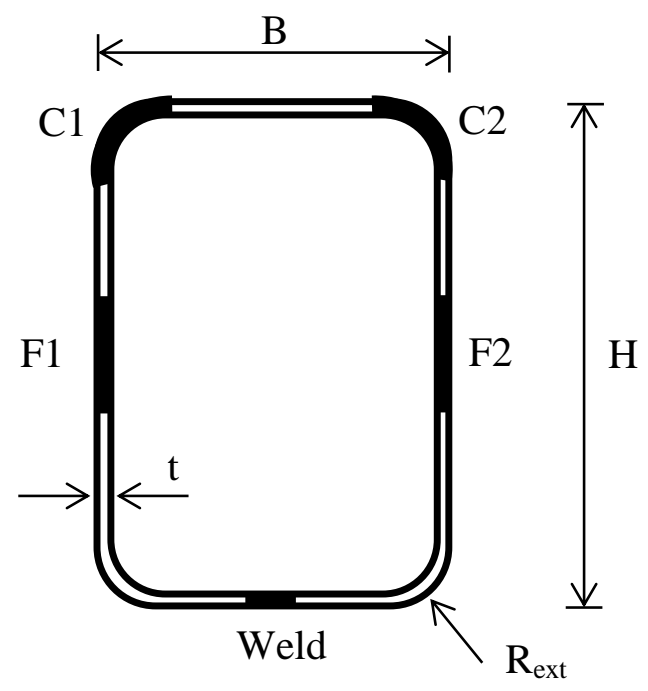

Figure 1. Location of flat and corner coupons and definition of cross-section symbols.

All the details regarding tensile tests have been widely described in Arrayago and Real [8], where an experimental programme on ferritic stainless steel RHS and SHS beams is presented. Since these tests were performed in the same ferritic grade and cross-sections, the material characterization reported in [8] is applicable to the tests presented in this paper. Average material properties for flat and corner coupons are presented in Table 1, where E is the Young's modulus, $\sigma_{0.05}, \sigma_{0.2}$ and $\sigma_{1.0}$ are the proof stresses corresponding to $0.05 \%, 0.2 \%$ and $1.0 \%$ plastic strains respectively, $\sigma_{\mathrm{u}}$ is the ultimate tensile strength, $\varepsilon_{\mathrm{u}}$ is the corresponding ultimate strain and $\varepsilon_{\mathrm{f}}$ is the strain at fracture, measured over the standard gauge length of $5.65 \sqrt{\mathrm{A}_{\mathrm{c}}}$, where $\mathrm{A}_{\mathrm{c}}$ is the cross-sectional area of the coupon. Strain hardening exponents $n$ and $m$ corresponding to the material model proposed by Mirambell and Real [9] are also provided, together with the $\mathrm{n}_{0.2-1.0}$ parameter of the material model proposed by Gardner and Ashraf [10] for compression. However, parameters corresponding to the material model in [10] could not be given for corner coupons since the reached plastic deformations were lower than $1 \%$. 
Table 1. Average tensile test results for different cross-sections.

\begin{tabular}{ccccccccccc}
\hline \hline & $\begin{array}{c}\mathrm{E} \\
{[\mathrm{MPa}]}\end{array}$ & $\begin{array}{c}\sigma_{0.05} \\
{[\mathrm{MPa}]}\end{array}$ & $\begin{array}{c}\sigma_{0.2} \\
{[\mathrm{MPa}]}\end{array}$ & $\begin{array}{c}\sigma_{1.0} \\
{[\mathrm{MPa}]}\end{array}$ & $\begin{array}{c}\sigma_{\mathrm{u}} \\
{[\mathrm{MPa}]}\end{array}$ & $\begin{array}{c}\varepsilon_{\mathrm{u}} \\
{[\%]}\end{array}$ & $\begin{array}{c}\varepsilon_{\mathrm{f}} \\
{[\%]}\end{array}$ & $\mathrm{n}$ & $\mathrm{n}_{0.2-1.0}$ & $\mathrm{~m}$ \\
\hline \hline $\mathrm{S} 1-\mathrm{F}$ & 173992 & 465 & 521 & 545 & 559 & 8.2 & 21.3 & 12.4 & 3.7 & 2.3 \\
$\mathrm{~S} 1-\mathrm{C}$ & 170049 & 441 & 577 & -- & 645 & 1.1 & 1.1 & 5.0 & -- & 5.4 \\
\hline $\mathrm{S} 2-\mathrm{F}$ & 186896 & 433 & 485 & 499 & 505 & 6.8 & 19.6 & 12.2 & 3.1 & 2.6 \\
$\mathrm{~S} 2-\mathrm{C}$ & 178049 & 459 & 555 & -- & 587 & 1.0 & 1.1 & 7.9 & -- & 5.2 \\
\hline $\mathrm{S} 3-\mathrm{F}$ & 181632 & 467 & 507 & 518 & 520 & 3.6 & 19.2 & 16.4 & 2.9 & 2.5 \\
$\mathrm{~S} 3-\mathrm{C}$ & 183684 & 434 & 558 & -- & 601 & 1.0 & 1.0 & 5.9 & -- & 4.5 \\
\hline $\mathrm{S} 4-\mathrm{F}$ & 176704 & 391 & 430 & 444 & 490 & 12.6 & 25.8 & 14.6 & 2.6 & 2.3 \\
$\mathrm{~S} 4-\mathrm{C}$ & 194611 & 457 & 540 & -- & 583 & 1.0 & 1.6 & 7.6 & -- & 4.8 \\
\hline $\mathrm{S} 5-\mathrm{F}$ & 179568 & 381 & 418 & 431 & 480 & 13.8 & 25.8 & 15.3 & 2.5 & 2.4 \\
$\mathrm{~S} 5-\mathrm{C}$ & 186026 & 466 & 552 & -- & 575 & 1.1 & 1.4 & 8.0 & -- & 4.6 \\
\hline \hline
\end{tabular}

Full measured stress-strain curves for the flat and corner specimens for S1 and S5 crosssections are presented in Figure 2. These figures, together with Table 1, clearly show the effect of the cold-forming effect on the stress-strain behaviour of stainless steel specimens: both the proof stress $\sigma_{0.2}$ and the ultimate tensile strength $\sigma_{\mathrm{u}}$ increase due to the cold-forming effect, while the ductility considerably decreases, as $\varepsilon_{\mathrm{u}}$ and $\varepsilon_{\mathrm{f}}$ decrease.

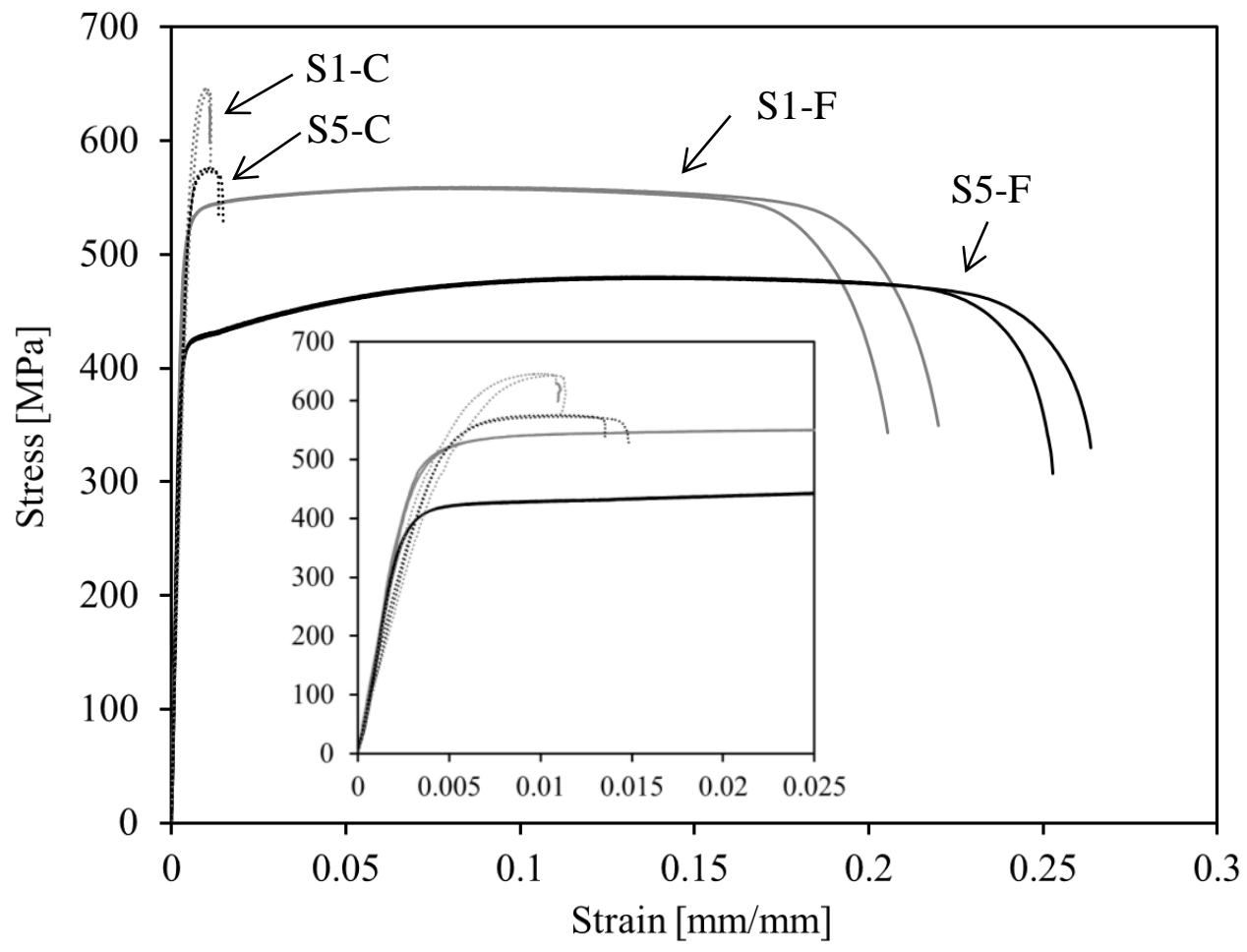

Figure 2. Measured stress-strain curves for S1 and S5 flat and corner coupons. 
In order to correctly analyse the experimental results, several authors $[11,12,13]$ define some weighted average material properties which consider the effect of the cold-forming processes and include both flat and corner mechanical properties. The calculation of these weighted average properties is simple, and consists of assigning the corresponding value of the material parameter to be calculated to the part of the cross-section considered, weighting it according to its area referred to the total area of the cross-section. The corner parts were considered to be composed by the curved portions at the corners plus the two adjacent segments of width equal to twice the thickness of the section according to [14], since corner properties are extended beyond the curved portion. The weighted average material properties of the different crosssections presented in this paper are summarized in Table 2 .

Table 2. Weighted average tensile material properties.

\begin{tabular}{cccccccc}
\hline & $\begin{array}{c}\mathrm{E} \\
{[\mathrm{MPa}]}\end{array}$ & $\begin{array}{c}\sigma_{0.05} \\
{[\mathrm{MPa}]}\end{array}$ & $\begin{array}{c}\sigma_{0.2} \\
{[\mathrm{MPa}]}\end{array}$ & $\begin{array}{c}\sigma_{\mathrm{u}} \\
{[\mathrm{MPa}]}\end{array}$ & $\begin{array}{c}\varepsilon_{\mathrm{u}} \\
{[\%]}\end{array}$ & $\mathrm{n}$ & $\mathrm{m}$ \\
\hline \hline S1 & 172615 & 456 & 539 & 587 & 5.8 & 8.8 & 2.6 \\
S2 & 183667 & 442 & 509 & 533 & 4.8 & 11.0 & 3.2 \\
S3 & 182637 & 451 & 529 & 554 & 2.5 & 12.9 & 2.7 \\
S4 & 188482 & 406 & 453 & 509 & 10.0 & 13.8 & 2.6 \\
S5 & 181030 & 400 & 449 & 502 & 10.8 & 14.7 & 2.4 \\
\hline \hline
\end{tabular}

Initial imperfections of every specimen were measured prior to testing. Since all the specimens presented in this paper are stub columns, only local imperfections were considered. The measurement of these imperfections was conducted by placing each specimen on a milling machine, and measuring the imperfections of the faces of the element at $90^{\circ}$ and $180^{\circ}$ angles from the weld while moving the milling machine (see Figure 3). The deviations were measured by a LVDT and recorded through a data acquisition system. All the obtained imperfections exhibited a half sine wave shape and the imperfection amplitude reported in Table 3 and Table 5 is the average value of the maximum imperfections from both faces. Imperfection amplitudes of the specimens to be tested under combined loading conditions were measured before the end 
plates were carefully welded, since the influence of the welding process was expected to be much smaller than the play in the testing system.

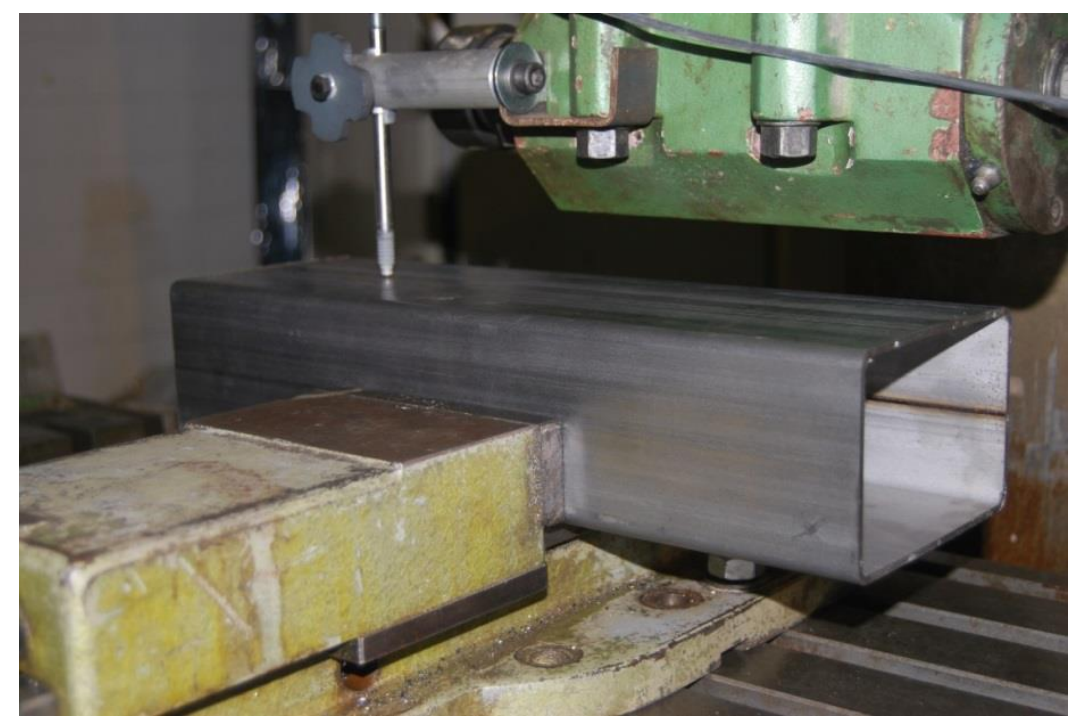

Figure 3. Setup for local geometric imperfection measurement.

\subsection{Compression tests}

Ten stub column tests conducted on ferritic stainless steel RHS and SHS subjected to compression are presented in this section. The tests were performed for the determination of the pure compression resistance of the five cross-sections, performing two compression tests for each cross-section in order to verify the repeatability of the obtained experimental values. Each stub column had a nominal length determined according to EN1993-1-3, Annex A [15], being 3 to 3.125 times the width of the widest plate element in order to avoid any overall buckling phenomena while guaranteeing that the desired failure by local buckling occurred. The real geometry of the specimens was accurately measured before performing the tests, as well as local initial imperfections. Table 3 presents the key geometrical parameters for the specimens tested under pure compression (labelled as $\mathrm{C}$ ), where $\mathrm{L}$ is the total length of the specimens, $\mathrm{H}$ is the total height, $B$ is the total width, $t$ is the thickness, $R_{\text {ext }}$ is the external corner radius and $w_{0}$ is the maximum amplitude of the measured local imperfections. The definition of the geometrical parameters is the one presented in Figure 1. 
Table 3. Measured dimensions in compression specimens.

\begin{tabular}{lcccccc}
\hline & $\begin{array}{c}\mathrm{L} \\
{[\mathrm{mm}]}\end{array}$ & $\begin{array}{c}\mathrm{H} \\
{[\mathrm{mm}]}\end{array}$ & $\begin{array}{c}\mathrm{B} \\
{[\mathrm{mm}]}\end{array}$ & $\begin{array}{c}\mathrm{t} \\
{[\mathrm{mm}]}\end{array}$ & $\begin{array}{c}\mathrm{R}_{\text {ext }}[\mathrm{mm}] \\
{[\mathrm{mm}]}\end{array}$ & $\begin{array}{c}\mathrm{W}_{\mathrm{o}} \\
{[\mathrm{mm}]}\end{array}$ \\
\hline S1-C1 & 249.8 & 79.9 & 79.9 & 3.8 & 8.6 & 0.023 \\
S1-C2 & 250.0 & 79.9 & 79.9 & 3.8 & 8.9 & 0.027 \\
\hline S2-C1 & 179.8 & 60.3 & 60.2 & 2.9 & 6.6 & 0.059 \\
S2-C2 & 180.0 & 60.1 & 60.1 & 2.9 & 6.3 & 0.058 \\
\hline S3-C1 & 249.5 & 80.0 & 39.9 & 3.9 & 7.6 & 0.043 \\
S3-C2 & 249.0 & 80.0 & 40.0 & 3.9 & 7.6 & 0.035 \\
\hline S4-C1 & 359.5 & 119.7 & 79.7 & 2.9 & 7.0 & 0.021 \\
S4-C2 & 359.5 & 119.9 & 79.7 & 2.9 & 6.6 & 0.011 \\
\hline S5-C1 & 210.0 & 70.1 & 49.9 & 2.0 & 4.3 & 0.025 \\
S5-C2 & 210.0 & 70.0 & 49.8 & 2.0 & 4.2 & 0.022 \\
\hline \hline
\end{tabular}

Stub column tests were performed at the Laboratori de Tecnologia d'Estructures Lluís Agulló, at Universitat Politècnica de Catalunya (UPC), in a 1000kN INSTRON machine where a uniform compression was introduced to the specimens through two parallel platens. All specimens were tested under pure compression and displacement control, at a constant rate of $0.5 \mathrm{~mm} / \mathrm{min}$, in order to reproduce the post-buckling behaviour of the specimens. The applied load was measured by the load cell of the testing machine, while the end shortening of the specimens was determined through three LVDT. One of the tests of each cross-section type was also instrumented by strain gauges: two strain gauges were attached to the widest faces of the RHS specimens, at mid-height and at a distance of four times the thickness from the external part of the elements; while for SHS specimens, the four faces were instrumented. The information was recorded by an MGCPlus data acquisition system at $2 \mathrm{~s}^{-1}$ intervals.

The measured strains allowed for a better understanding of the behaviour of the cross-sections and also provided the necessary information for the correction of the experimental load-end shortening curves, as recommended in [16], removing the effect of the elastic deformation of the end platens. All the specimens failed by local buckling, as presented in Figure 4. The corrected experimental results for all compression tests are summarized and presented in Table 
4, where $\mathrm{N}_{\mathrm{u}}$ is the achieved ultimate compression load, $\delta_{\mathrm{u}}$ is the end shortening at $\mathrm{N}_{\mathrm{u}}$ and $\mathrm{N}_{\mathrm{u}} / \mathrm{A} \sigma_{0.2}$ compares the ultimate compression resistance of the cross-section with the corresponding squash load, calculated considering the weighted average material properties given in Table 2.
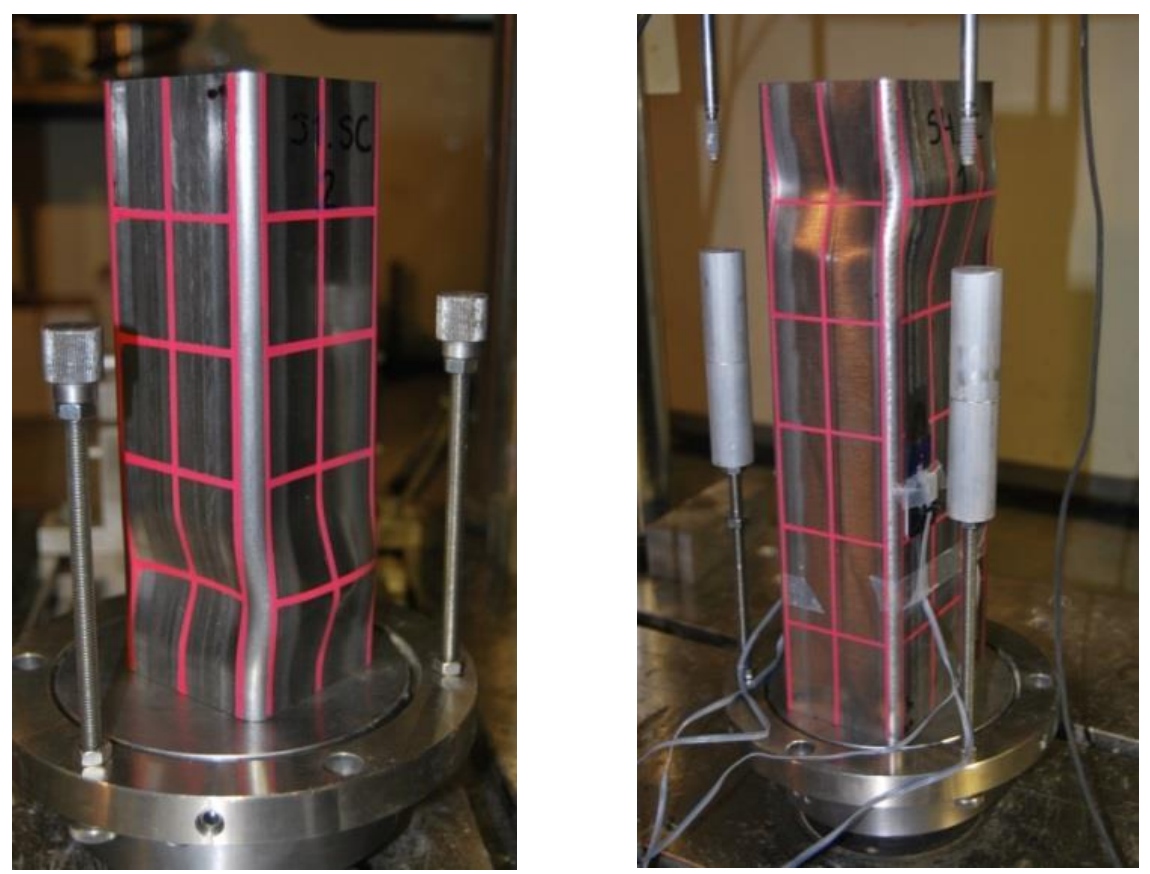

Figure 4. Compression failure modes for S1 and S4 specimens.

Table 4. Summary of test results for compression tests.

\begin{tabular}{lccc}
\hline \hline Specimen & $\mathrm{N}_{\mathrm{u}}[\mathrm{kN}]$ & $\delta_{\mathrm{u}}[\mathrm{mm}]$ & $\mathrm{N}_{\mathrm{u}} / \mathrm{A} \sigma_{0.2}$ \\
\hline $\mathrm{S} 1-\mathrm{C} 1$ & 654.6 & 2.7 & 1.09 \\
$\mathrm{~S} 1-\mathrm{C} 2$ & 655.2 & 2.9 & 1.11 \\
\hline $\mathrm{S} 2-\mathrm{C} 1$ & 342.6 & 2.7 & 1.07 \\
$\mathrm{~S} 2-\mathrm{C} 2$ & 342.8 & 2.0 & 1.05 \\
\hline $\mathrm{S} 3-\mathrm{C} 1$ & 465.2 & 3.0 & 1.05 \\
$\mathrm{~S} 3-\mathrm{C} 2$ & 465.1 & 2.8 & 1.05 \\
\hline $\mathrm{S} 4-\mathrm{C} 1$ & 443.1 & 1.3 & 0.89 \\
$\mathrm{~S} 4-\mathrm{C} 2$ & 450.4 & 1.3 & 0.91 \\
\hline $\mathrm{S} 5-\mathrm{C} 1$ & 190.1 & 0.9 & 0.94 \\
$\mathrm{~S} 5-\mathrm{C} 2$ & 190.1 & 0.9 & 0.94 \\
\hline \hline
\end{tabular}

The full load-corrected end shortening curves representing the pure compression response of the tested specimens are presented in Figure 5, where a minimum scatter between the two tests corresponding to the same cross-section indicate the reliability of the conducted tests. The 
consideration of the normalized load-end shortening response of each specimen as depicted in Figure 6 highlights the different behaviours of stocky cross-sections (S1, S2 and S3), with a more ductile post-buckling response, against the slender ones (S4 and S5), where the descending part of the diagram is steeper.

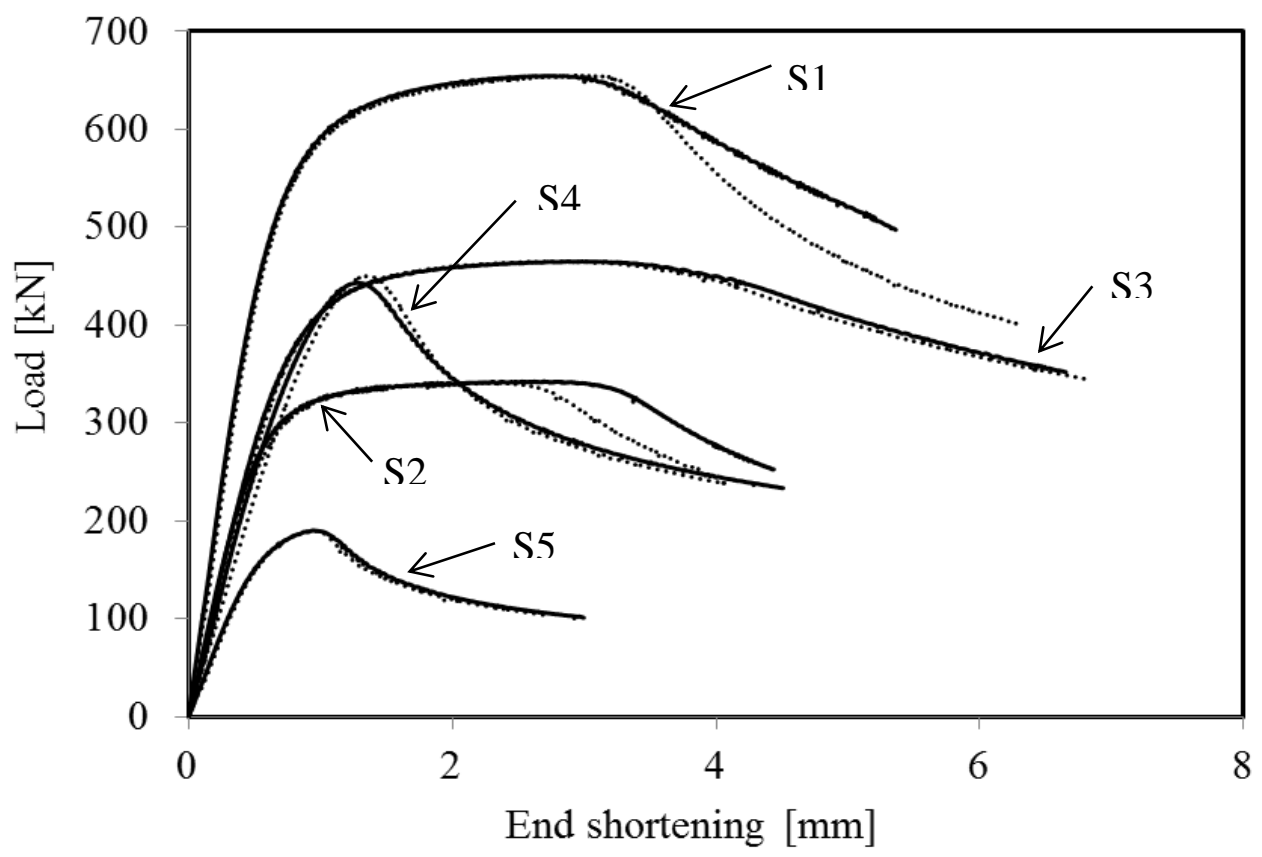

Figure 5. Load end-shortening curves of tested specimens.

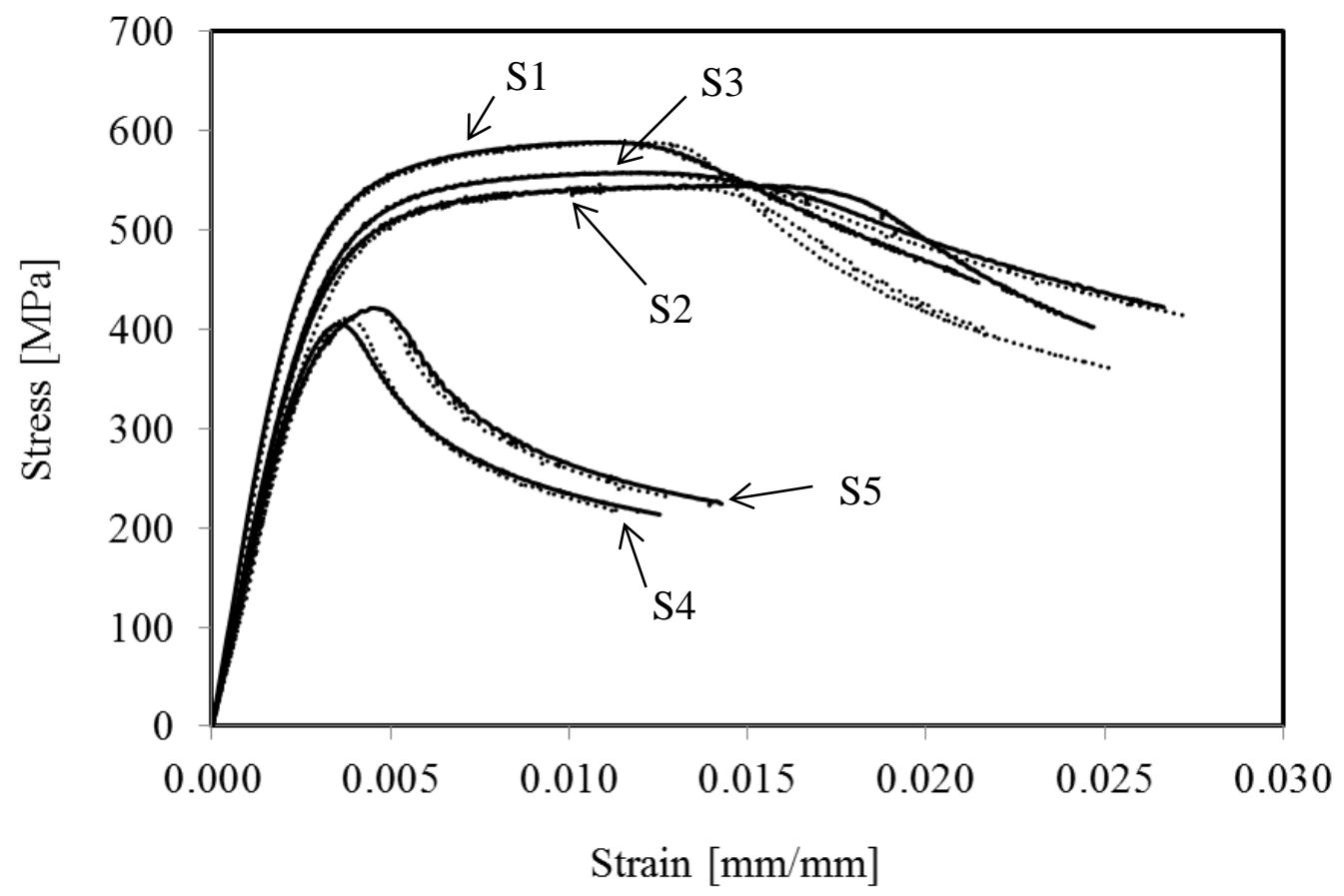

Figure 6.Normalized load-end shortening response of tested specimens. 


\subsection{Combined loading tests}

The ultimate resistance of ferritic stainless steel RHS and SHS subjected to combined axial compression and bending moment loading conditions is also investigated in this paper. Two specimens were tested for each cross-section and loading condition in this experimental programme: while two specimens were tested for SHS, four specimens were considered for RHS as both bending axes were studied. Therefore, a total of 16 elements were tested. The measured dimensions of the specimens are presented in Table 5, where the notation is the one introduced in Figure 1, $\mathrm{L}$ is the total length of the specimen and $\mathrm{w}_{0}$ represents the maximum measured imperfection amplitude. Combined loading tests concerning major axis $(\mathrm{Mj})$ bending have been labelled as CL1 and CL2, while tests about minor axis (Mi) have been labelled CL3 and CL4. Specimens had nominal lengths of between 3 and 6.25 times the width of the corresponding plate element depending on the studied axis.

Table 5. Measured dimensions in combined loading specimens.

\begin{tabular}{lccccccc}
\hline \hline & $\begin{array}{c}\text { Axis of } \\
\text { bending }\end{array}$ & $\begin{array}{c}\mathrm{L} \\
{[\mathrm{mm}]}\end{array}$ & $\begin{array}{c}\mathrm{H} \\
{[\mathrm{mm}]}\end{array}$ & $\begin{array}{c}\mathrm{B} \\
{[\mathrm{mm}]}\end{array}$ & $\begin{array}{c}\mathrm{t} \\
{[\mathrm{mm}]}\end{array}$ & $\begin{array}{c}\mathrm{R}_{\text {ext }} \\
{[\mathrm{mm}]}\end{array}$ & $\begin{array}{c}\mathrm{W}_{\mathrm{o}} \\
{[\mathrm{mm}]}\end{array}$ \\
\hline \hline S1-CL1 & -- & 249.8 & 79.9 & 79.9 & 3.9 & 8.3 & 0.026 \\
S1-CL2 & -- & 250.0 & 80.2 & 80.3 & 3.8 & 8.5 & 0.024 \\
\hline S2-CL1 & -- & 180.0 & 60.1 & 60.1 & 2.9 & 6.5 & 0.028 \\
S2-CL2 & -- & 180.0 & 60.1 & 60.1 & 2.9 & 6.4 & 0.024 \\
\hline S3-CL1 & Major & 249.3 & 80.0 & 39.9 & 3.8 & 7.6 & 0.006 \\
S3-CL2 & Major & 249.0 & 80.0 & 40.0 & 3.8 & 7.7 & 0.023 \\
S3-CL3 & Minor & 249.8 & 79.9 & 39.9 & 3.8 & 7.7 & 0.031 \\
S3-CL4 & Minor & 249.8 & 80.0 & 40.0 & 3.8 & 8.1 & 0.030 \\
\hline S4-CL1 & Major & 359.5 & 119.9 & 79.7 & 3.0 & 6.5 & 0.020 \\
S4-CL2 & Major & 359.5 & 119.8 & 79.7 & 2.9 & 6.6 & 0.016 \\
S4-CL3 & Minor & 360.0 & 119.9 & 79.7 & 2.9 & 7.0 & 0.018 \\
S4-CL4 & Minor & 360.0 & 119.9 & 79.9 & 3.0 & 7.7 & 0.014 \\
\hline S5-CL1 & Major & 210.0 & 70.0 & 49.8 & 2.0 & 4.2 & 0.027 \\
S5-CL2 & Major & 210.0 & 70.0 & 49.8 & 2.0 & 4.2 & 0.037 \\
S5-CL3 & Minor & 209.5 & 70.2 & 49.8 & 2.0 & 4.2 & 0.038 \\
S5-CL4 & Minor & 210.0 & 70.0 & 49.8 & 2.0 & 4.3 & 0.035 \\
\hline \hline
\end{tabular}

All tests were conducted in a $1000 \mathrm{kN}$ INSTRON machine, where a compressive load was eccentrically introduced into the specimens through two parallel platens, subjecting the cross- 
sections to a combination of axial compression and bending moment. The compression platens of the testing machine were fixed against all rotations, and the needed degrees of freedom were arranged separately. Two steel end plates were welded to each specimen at both extremes with the corresponding eccentricity and these end plates were connected to knife edges, allowing rotations about the studied axis. Triangular-shaped grooves with a depth of $9 \mathrm{~mm}$ were machined in order to guarantee pin-ended boundary conditions, with a groove showing an angle of $100^{\circ}$ and a triangular bar with an angle of $60^{\circ}$, as presented in Figure 7.

The axial load was introduced to the outer faces of the specimens, as the considered nominal eccentricity was equal to the half of the height or width $(\mathrm{H} / 2$ or $\mathrm{B} / 2$, respectively), depending on the studied axis (see Figure 7). Tests were carried out under displacement control in order to reproduce the post-buckling behaviour of the specimens, at a testing rate of $0.25 \mathrm{~mm} / \mathrm{min}$. The instrumentation is presented in Figure 7(a) and consisted of one LVDT measuring the end shortening at the loading line, a load cell for the measurement of the applied load, strain-gauges for the determination of the compressive and tensile strains at the extreme fibres and two inclinometers, fixed to both steel end plates, measuring end rotations. An additional LVDT measuring the lateral deflection of the compressed face at mid-height was also included in order to obtain the second order effects for each specimen. Strain gauges were placed in a similar position to the ones presented for compression stub column tests, at the mid-height section, at a distance of four times the cross-sectional thickness from the corners. Figure 7(b) shows the failure for S2-CL1 specimen, which failed by local buckling of the flat elements at mid-height section. The full experimental load-end rotation curves are presented in Figures 8(a) to 8(d) for the different cross-sections subjected to uniaxial bending and compression loading conditions. 


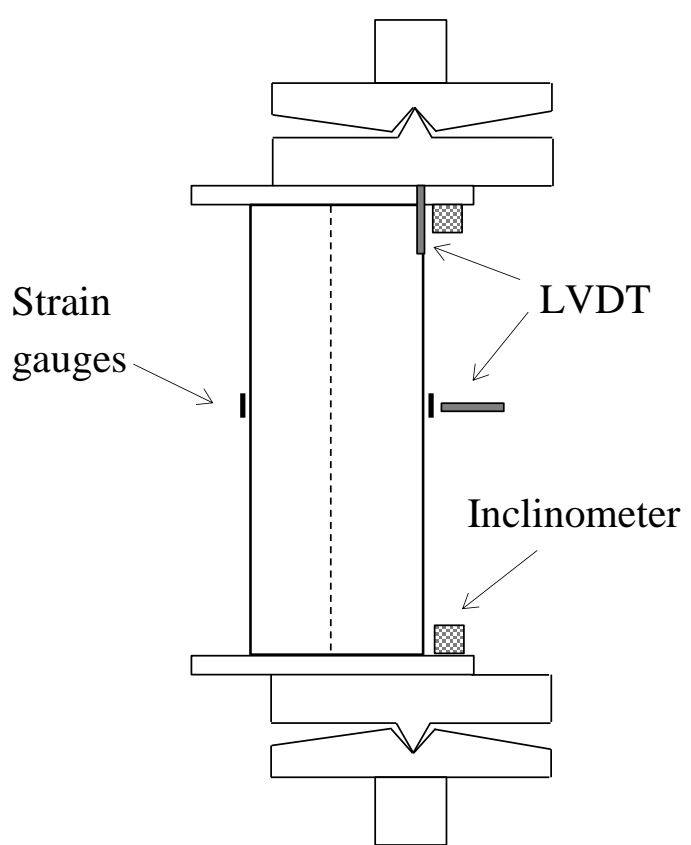

a) Schematic diagram of the test setup.

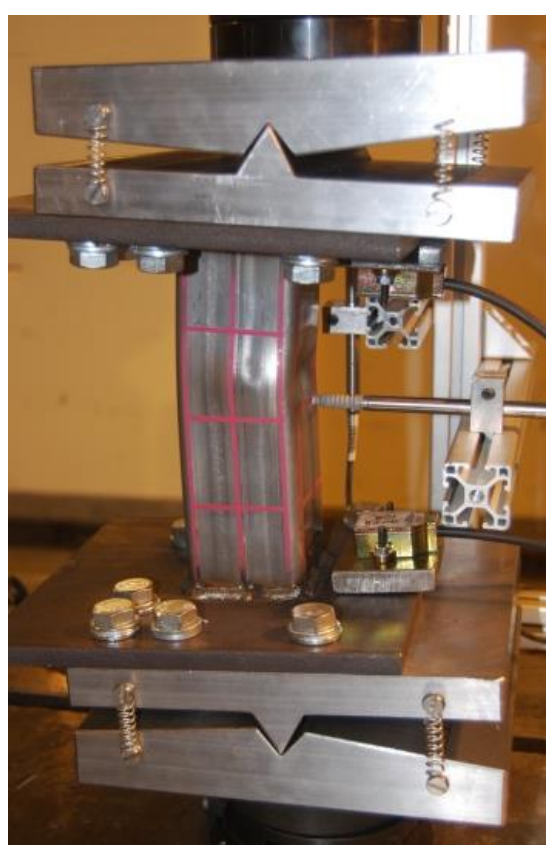

b) Testing of S2-CL1 specimen.

Figure 7. Combined loading test configuration.

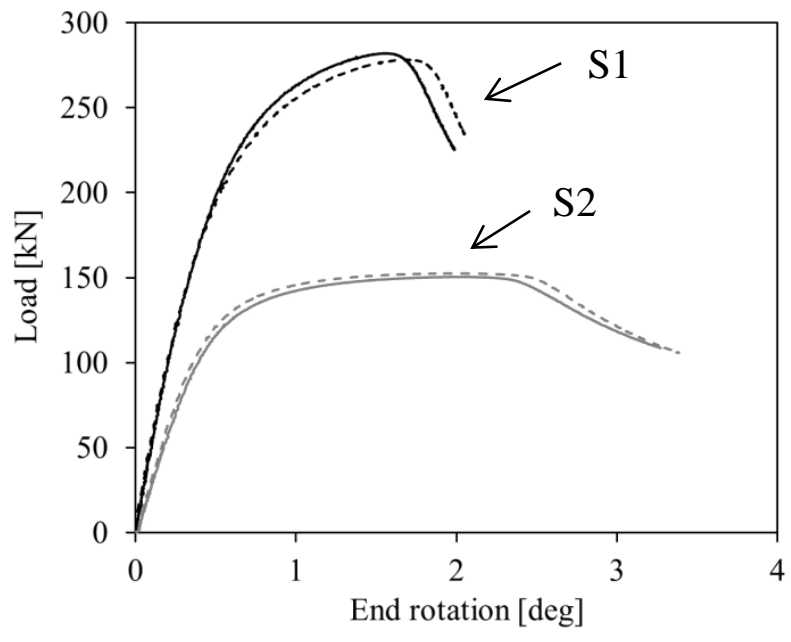

a) Test curves for $\mathrm{S} 1$ and $\mathrm{S} 2$.

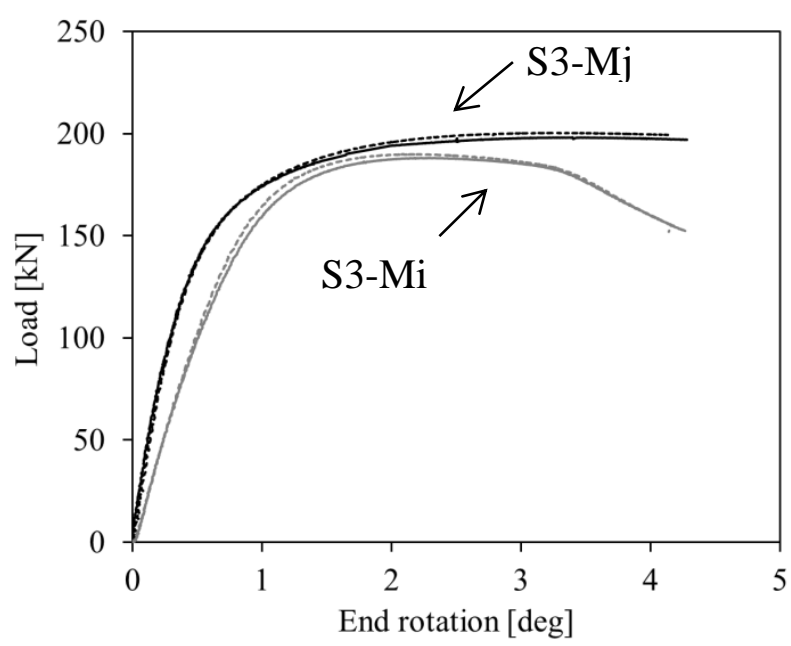

b) Test curves for S3-Mj and S3-Mi. 


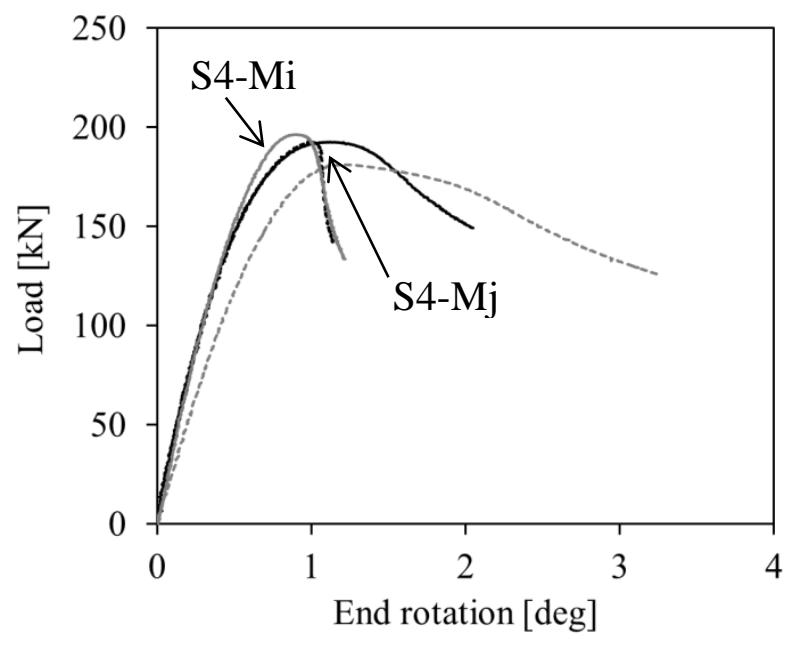

c) Test curves for $\mathrm{S} 4-\mathrm{Mj}$ and $\mathrm{S} 4-\mathrm{Mi}$.

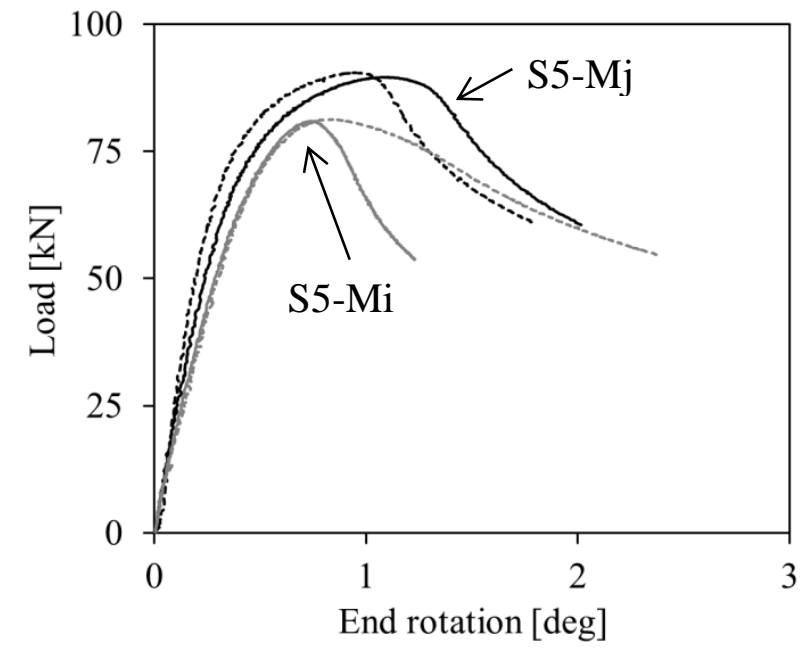

d) Test curves for S5-Mj and S5-Mi.

Figure 8. Measured load-end rotation curves for combined compression and bending tests.

Test results are reported in Table 6, where the maximum applied load $F_{u}$ of each conducted tests is shown together with the corresponding end-shortening $\delta_{\mathrm{u}}$, end rotation $\theta_{\mathrm{u}}$, the measured load eccentricity $\mathrm{e}_{\mathrm{m}}$ and the lateral deflection at failure e'. As mentioned before, some of the specimens tested under combined loading conditions were instrumented with strain gauges measuring the strains at the extreme fibres of the cross-section at the mid-height section. These strain measurements allowed for the calculation of the axial and flexural strains (Eq. (1) and (2) respectively), and therefore, the determination of the calculated load eccentricities $\mathrm{e}_{0}$ introduced into the specimens and compare them with the corresponding measured eccentricities.

$\varepsilon_{\mathrm{N}}=\frac{\varepsilon_{\max }+\varepsilon_{\min }}{2}$

$\varepsilon_{\mathrm{M}}=\frac{\varepsilon_{\max }-\varepsilon_{\min }}{2}$

where $\varepsilon_{\max }$ is the measured strain at the maximum compressed fibre and $\varepsilon_{\min }$ the measured maximum tensile or minimum compressive strain at the other extreme fibre. If the bending moment at each loading step is considered to be a function of both the initial eccentricity $\mathrm{e}_{0}$ and the lateral deflection or second order eccentricity e' and the applied axial load F, and the 
expression relating the total bending moment with the flexural strain is considered, $\mathrm{M}_{\mathrm{T}}=\mathrm{F}\left(\mathrm{e}_{0}+\mathrm{e}^{\prime}\right)=\mathrm{EI} \kappa$, the experimental load eccentricity can be calculated. The curvature is given by $\kappa=\varepsilon_{M} / 0.5 \mathrm{~d}$, where $\mathrm{d}$ is the outer dimension of the element, equal to the height $\mathrm{H}$ when major axis tests are considered and equal to B for minor axis tests; E is the Young's modulus and I the relevant second moment of area. Therefore, the determination of the calculated eccentricity can be derived through Eq. (3). Note that since Eq. (3) is only applicable in the elastic range of the material, the calculated eccentricities have been determined as the average values of the eccentricities obtained while the material behaved elastically, for low load values.

$\mathrm{e}_{0}=\frac{\mathrm{EI}\left(\varepsilon_{\max }-\varepsilon_{\min }\right)}{\mathrm{d} \cdot \mathrm{F}}-\mathrm{e}^{\prime}$

Three different bending moment values associated with the ultimate loads are provided for each specimen in Table 6: $M_{1}$ represents the first order bending moment due to the eccentricity of the applied force, calculated as $\mathrm{M}_{1}=\mathrm{F}_{\mathrm{u}} \cdot \mathrm{e}_{0}$, while $\mathrm{M}_{2}$ represents the bending moment due to second order effects, calculated as $\mathrm{M}_{2}=\mathrm{F}_{\mathrm{u}} \cdot \mathrm{e}$ '. $\mathrm{M}_{\mathrm{T}}$ represents, therefore, the total bending moment, being $\mathrm{M}_{\mathrm{T}}=\mathrm{M}_{1}+\mathrm{M}_{2}$. For those specimens where strain gauge measurements were available, $\mathrm{M}_{1}$ moments were calculated by using the calculated eccentricities $\mathrm{e}_{0}$, but for the others the measured eccentricities $\mathrm{e}_{\mathrm{m}}$ were used.

Table 6. Summary of test results for combined loading tests.

\begin{tabular}{lcccccccccc}
\hline \hline & $\begin{array}{c}\text { Axis of } \\
\text { bending }\end{array}$ & $\begin{array}{c}\mathrm{F}_{\mathrm{u}} \\
{[\mathrm{kN}]}\end{array}$ & $\begin{array}{c}\delta_{\mathrm{u}} \\
{[\mathrm{mm}]}\end{array}$ & $\begin{array}{c}\theta_{\mathrm{u}} \\
{[\mathrm{deg}]}\end{array}$ & $\begin{array}{c}\mathrm{e}_{\mathrm{m}} \\
{[\mathrm{mm}]}\end{array}$ & $\begin{array}{c}\mathrm{e}^{\prime} \\
{[\mathrm{mm}]}\end{array}$ & $\begin{array}{c}\mathrm{e}_{0} \\
{[\mathrm{~mm}]}\end{array}$ & $\begin{array}{c}\mathrm{M}_{\mathrm{T}} \\
{[\mathrm{kNm}]}\end{array}$ & $\begin{array}{c}\mathrm{M}_{1} \\
{[\mathrm{kNm}]}\end{array}$ & $\begin{array}{c}\mathrm{M}_{2} \\
{[\mathrm{kNm}]}\end{array}$ \\
\hline \hline S1-CL1 & -- & 282.0 & 4.2 & 1.80 & 38.9 & 2.6 & 38.1 & 11.5 & 10.7 & 0.7 \\
S1-CL2 & -- & 278.3 & 4.4 & 1.93 & 39.7 & 2.7 & -- & 11.8 & 11.0 & 0.8 \\
S2-CL1 & -- & 150.4 & 4.3 & 2.01 & 29.5 & 3.5 & 29.4 & 4.9 & 4.4 & 0.5 \\
S2-CL2 & -- & 152.6 & 4.5 & 2.05 & 28.7 & 3.6 & -- & 4.9 & 4.4 & 0.5 \\
\hline S3-CL1 & Major & 198.2 & 7.5 & 3.40 & 39.0 & 5.2 & 37.0 & 8.4 & 7.3 & 1.0 \\
S3-CL2 & Major & 200.3 & 8.0 & 3.22 & 38.5 & 5.9 & -- & 8.9 & 7.7 & 1.2 \\
S3-CL3 & Minor & 188.1 & 3.7 & 2.19 & 19.9 & 4.4 & 18.3 & 4.3 & 3.4 & 0.8 \\
S3-CL4 & Minor & 189.9 & 3.5 & 2.10 & 19.5 & 4.2 & -- & 4.5 & 3.7 & 0.8 \\
\hline
\end{tabular}




\begin{tabular}{lllllllllll}
\hline S4-CL1 & Major & 192.6 & 3.2 & 1.12 & 59.4 & 1.7 & 57.5 & 11.4 & 11.1 & 0.3 \\
S4-CL2 & Major & 192.9 & 3.1 & 0.98 & 59.6 & 1.8 & -- & 11.8 & 11.5 & 0.3 \\
S4-CL3 & Minor & 196.3 & 2.7 & 0.90 & 39.3 & 2.2 & 37.4 & 7.8 & 7.3 & 0.4 \\
S4-CL4 & Minor & 181.1 & 2.6 & 1.19 & 38.7 & 2.0 & -- & 7.4 & 7.0 & 0.4 \\
\hline S5-CL1 & Major & 89.6 & 2.8 & 1.10 & 35.5 & 2.2 & 37.1 & 3.5 & 3.3 & 0.2 \\
S5-CL2 & Major & 90.4 & 2.6 & 0.93 & 35.1 & 2.0 & -- & 3.4 & 3.2 & 0.2 \\
S5-CL3 & Minor & 81.2 & 1.7 & 0.75 & 23.4 & 1.4 & 22.8 & 2.0 & 1.8 & 0.1 \\
S5-CL4 & Minor & 80.9 & 1.6 & 0.83 & 23.7 & 1.3 & -- & 2.0 & 1.9 & 0.1 \\
\hline \hline
\end{tabular}

*A problem occurred in the connexion between the steel end plates and the hinges.

\section{Analysis of compression test results}

\subsection{Introduction}

The European structural stainless steel design Standard EN1993-1-4 [2] accounts for the effect of local buckling through the cross-section classification concept given in EN1993-1-1 [17]. The assessment of the Class 3 limits is presented in this section for the cross-sections tested under pure compression, together with the comparison of the experimental ultimate loads with those calculated according to [2] and the Continuous Strength Method.

Two different cross-sectional classifications have been considered, the one currently codified in EN1993-1-4 [2] and the revised one proposed by Gardner and Theofanous [18] for stainless steels, some of which will be included in future revisions of [2]. Additionally, the assessment of the predicted ultimate compression loads has been conducted in this section, by using the expressions given in [2], which depend on cross-sectional classification, and the ones proposed for the CSM, which only depend on cross-sectional slenderness, but not on its classification.

\subsection{Class 3 limit assessment}

The assessment of the Class 3 limit currently codified in EN1993-1-4 [2] and the one proposed by Gardner and Theofanous [18] is investigated through the comparison of the experimental ultimate compression capacities with the corresponding squash loads of the cross-sections, calculated as $\mathrm{N}_{\mathrm{pl}}=\mathrm{A} \sigma_{0.2}$, where $\mathrm{A}$ is the cross-sectional area and $\sigma_{0.2}$ is the $0.2 \%$ proof stress, 
considered as the weighted average $\sigma_{0.2}$ presented in Table 2. The Class of a cross-section is usually determined in terms of its c/ct slenderness, considering both geometrical and material properties of the studied element, where $\mathrm{c}$ is the width or depth of a part of a cross-section, $\mathrm{t}$ is the element thickness and $\varepsilon$ considers material properties, defined as $\varepsilon=\left[\left(235 / \sigma_{0.2}\right) \cdot(\mathrm{E} / 210000)\right]^{0.5}$. Cross-sectional limit for Class 3 currently codified in [2] is $\mathrm{c} / \varepsilon t<30.7$, while the revised and less conservative limit proposed in [18] stands for $\mathrm{c} / \varepsilon t<37$.

The normalized experimental ultimate loads are plotted against the cross-sectional slenderness $\mathrm{c} / \mathrm{t} \varepsilon$ in Figure 9 . According to Class 3 cross-section definition, every cross-section able to reach the plastic axial compression resistance (or equivalently, the $\mathrm{N}_{\mathrm{u}} / \mathrm{N}_{\mathrm{pl}}$ ratio is higher than 1) is Class 3 or better. Since slenderness values obtained for the tested specimens are far from the Class 3 limit $c / \varepsilon t<37$, the trend line of the experimental results has also been presented. Figure 9 confirms that both considered classifications provide safe Class 3 predictions, although the revised limit presented by [18] seems to be more accurate for ferritic stainless steel RHS and SHS, as highlighted before by $[12,13,19]$.

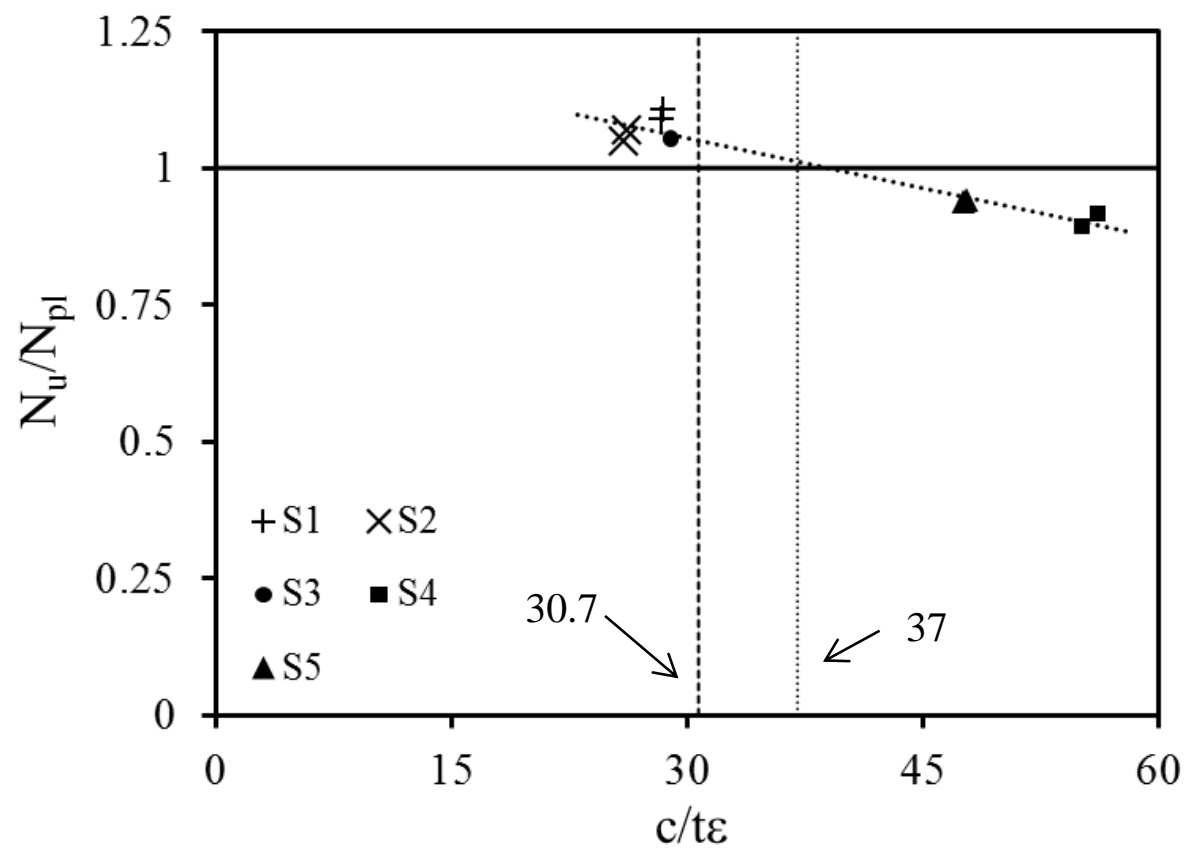

Figure 9. Class 3 limit assessment. 


\subsection{EN1993-1-4 and CSM assessment for compression}

The classical EN1993-1-4 [2] approach for the determination of the ultimate resistance capacity of a cross-section, as mentioned before, depends on cross-sectional classification, as given in Eqs. (4)-(5). Regarding uniform compression, cross-sections achieving their plastic capacities before failure are considered to be fully effective, and are considered to be Class 3 or better. For cross-sections classified as Class 4, the effective cross-sectional area needs to be considered for the calculation of their compression resistance.

$\mathrm{N}_{\mathrm{Rd}}=\mathrm{A} \cdot \sigma_{0.2} \quad$ for Class 1 to 3 cross-sections

$\mathrm{N}_{\mathrm{Rd}}=\mathrm{A}_{\mathrm{eff}} \cdot \sigma_{0.2}$ for Class 4 cross-sections

where $\sigma_{0.2}$ is the $0.2 \%$ proof stress, $\mathrm{A}$ is the cross-sectional area and $\mathrm{A}_{\text {eff }}$ is the effective crosssectional area. When a Class 4 cross-section is analysed, the effective area might be calculated through Eqs. (6) and (7) if EN 1993-1-4 [2] cross-sectional classification is considered, and through Eqs. (7) and (8) for the Gardner and Theofanous [18] proposal.

$\rho=\frac{0.772}{\bar{\lambda}_{p}}-\frac{0.125}{\bar{\lambda}_{p}^{2}} \leq 1.0$

$\overline{\lambda_{\mathrm{p}}}=\frac{\overline{\mathrm{b}} / \mathrm{t}}{28.4 \varepsilon \sqrt{\mathrm{k}_{\sigma}}}$ and $\mathrm{k}_{\sigma}=4$ for compression

$\rho=\frac{0.772}{\bar{\lambda}_{p}}-\frac{0.079}{\bar{\lambda}_{p}^{2}} \leq 1.0$

Additionally, the ultimate resistance of stocky cross-sections subjected to axial compression can be more accurately determined through a new design method based on cross-section deformation capacity, the Continuous Strength Method, which also considers strain hardening effects. The maximum strain that a cross-section can reach $\varepsilon_{\mathrm{CSM}}$ is evaluated in terms of its relative slenderness $\bar{\lambda}_{\mathrm{p}}$ and the yield strain $\varepsilon_{\mathrm{y}}$, as shown in Eq. (9), which was adjusted 
considering both stub column and beam test data by Afshan and Gardner [3]. The relative slenderness for each fundamental loading case can be obtained from Eq. (10), where $\sigma_{\mathrm{cr}}$ is the critical buckling stress, obtained from the lowest buckling mode in an eigenvalue analysis. At the same time $\bar{\lambda}_{p}$ can be also calculated according to EN 1993-1-4 [2] for the most slender plate element in the cross-section. It should be noted that the former procedure accounts for element interaction whereas the latter does not. The $\bar{\lambda}_{\mathrm{p}} \leq 0.68$ limit is adopted given that, beyond this limit, there is no significant benefit of considering material strain hardening effects.

$$
\begin{aligned}
& \frac{\varepsilon_{\mathrm{CSM}}}{\varepsilon_{\mathrm{y}}}=\frac{0.25}{\bar{\lambda}_{\mathrm{p}}^{3.6}} \text { but } \frac{\varepsilon_{\mathrm{CSM}}}{\varepsilon_{\mathrm{y}}}<\min \left(15, \frac{0.4 \varepsilon_{\mathrm{u}}}{\varepsilon_{\mathrm{y}}}\right) \\
& \bar{\lambda}_{\mathrm{p}}=\sqrt{\frac{\sigma_{0.2}}{\sigma_{\mathrm{cr}}}} \text { but } \bar{\lambda}_{\mathrm{p}} \leq 0.68
\end{aligned}
$$

Cross-sectional capacities are derived from the $\sigma_{\mathrm{CSM}}$ stress reached at the maximum strain $\varepsilon_{\mathrm{CSM}}$. The expression for the determination of the resistances of the cross-sections subjected to pure compression is presented in Eq. (11).

$\mathrm{N}_{\mathrm{CSM}}=\mathrm{A} \cdot \sigma_{\mathrm{CSM}}$

where $\mathrm{A}$ is the gross cross-sectional area and $\sigma_{\mathrm{CSM}}$ is the limiting stress. This stress $\sigma_{\mathrm{CSM}}$ can be determined from a simplified bilinear material model also considering material strain-hardening and given by Eq. (12), which was first developed for austenitic and duplex stainless steels in Ashraf and Gardner [3] and afterwards revised for ferritics in Bock et al. [19], as given in Eq. (13).

$\sigma_{\mathrm{CSM}}=\sigma_{0.2}+\mathrm{E}_{\mathrm{sh}} \varepsilon_{\mathrm{y}}\left(\frac{\varepsilon_{\mathrm{CSM}}}{\varepsilon_{\mathrm{y}}}-1\right)$ 


$$
\mathrm{E}_{\mathrm{sh}}=\left\{\begin{array}{lll}
\frac{\sigma_{\mathrm{u}}-\sigma_{0.2}}{0.45 \varepsilon_{\mathrm{u}}-\varepsilon_{\mathrm{y}}} & \text { if } & \frac{\varepsilon_{\mathrm{y}}}{\varepsilon_{\mathrm{u}}}<0.45 \\
0 & \text { if } & \frac{\varepsilon_{\mathrm{y}}}{\varepsilon_{\mathrm{u}}}>0.45
\end{array}\right.
$$

The assessment of the predicting expressions codified in EN1993-1-4 [2] assuming crosssectional classifications is presented in Table 7, where $\mathrm{N}_{\mathrm{EN}}$ is the predicted compression resistance considering the current classification in [2] whereas $\mathrm{N}_{\mathrm{EN}, \mathrm{rev}}$ considers the revised class limits. Ultimate loads predicted by the CSM calculated using Eq. (11) are also presented. Cross-sectional slenderness were calculated considering $\sigma_{\mathrm{cr}}$ values from an elastic buckling analysis derived from CUFSM [20] and it is important to highlight that, as cross-sectional slenderness is higher than $\bar{\lambda}_{\mathrm{p}}=0.68$ for S4 and S5 cross-sections, CSM is not applicable.

Table 7. Assessment of EN 1993-1-4 and CSM predicting expressions for compression.

\begin{tabular}{ccccccc}
\hline \hline & $\begin{array}{c}\text { EN 1993-1-4 [2] } \\
\text { (Eqs. 4-5) }\end{array}$ & \multicolumn{2}{c}{$\begin{array}{c}\text { EN 1993-1-4 } \\
\text { Revised limits [18] } \\
(\text { Eqs. 4-5) }\end{array}$} & $\begin{array}{c}\text { CSM } \\
(\text { Eq. 11) }\end{array}$ \\
\hline \hline Specimen & $\begin{array}{c}\mathrm{N}_{\mathrm{EN}} \\
{[\mathrm{kN}]}\end{array}$ & $\mathrm{N}_{\mathrm{EN}} / \mathrm{N}_{\mathrm{u}}$ & $\begin{array}{c}\mathrm{N}_{\mathrm{EN}, \text { rev }} \\
{[\mathrm{kN}]}\end{array}$ & $\mathrm{N}_{\mathrm{EN}, \mathrm{rev}} / \mathrm{N}_{\mathrm{u}}$ & $\begin{array}{c}\mathrm{N}_{\mathrm{CSM}} \\
{[\mathrm{kN}]}\end{array}$ & $\mathrm{N}_{\mathrm{CSM}} / \mathrm{N}_{\mathrm{u}}$ \\
\hline $\mathrm{S} 1-\mathrm{C} 1$ & 583.1 & 0.89 & 583.1 & 0.89 & 603.0 & 0.92 \\
$\mathrm{~S} 1-\mathrm{C} 2$ & 574.6 & 0.88 & 574.6 & 0.88 & 594.5 & 0.91 \\
\hline $\mathrm{S} 2-\mathrm{C} 1$ & 308.3 & 0.90 & 308.3 & 0.90 & 321.4 & 0.94 \\
$\mathrm{~S} 2-\mathrm{C} 2$ & 314.8 & 0.92 & 314.8 & 0.92 & 328.0 & 0.96 \\
\hline $\mathrm{S} 3-\mathrm{C} 1$ & 425.5 & 0.91 & 425.5 & 0.91 & 452.2 & 0.97 \\
$\mathrm{~S} 3-\mathrm{C} 2$ & 424.3 & 0.91 & 424.3 & 0.91 & 451.0 & 0.97 \\
\hline $\mathrm{S} 4-\mathrm{C} 1$ & 437.2 & 0.99 & 444.0 & 1.00 & -- & -- \\
$\mathrm{S} 4-\mathrm{C} 2$ & 433.4 & 0.96 & 440.0 & 0.98 & -- & -- \\
\hline S5 - C1 & 181.8 & 0.96 & 185.6 & 0.98 & -- & -- \\
S5-C2 & 181.4 & 0.95 & 185.1 & 0.97 & -- & - \\
\hline Mean & & 0.93 & & 0.93 & & 0.94 \\
COV. & & 0.038 & & 0.047 & & 0.028 \\
\hline \hline
\end{tabular}

As it is demonstrated in Table 7, predicted ultimate loads are equal for both the original classification limits and the revised ones [18] regarding S1, S2 and S3 cross-sections, as none of the tested specimens presents a c/ct ratio between 30.7 and 37 , providing safe but quite conservative results. However, slightly different values are obtained for S4 and S5, since the 
considered classification approaches provide different effective area calculations through Eqs. (6) and (8). Concerning CSM, it is appreciated that for the cross-sections where this method is applicable, the predicted compression resistances are more accurate, and also present lower scatter, being therefore more appropriate for the stockiest ferritic stainless steel RHS and SHS studied in this paper.

\section{Analysis of combined loading test results}

\subsection{Introduction}

In order to investigate the most appropriate approach for the consideration of combined axial compression and uniaxial bending on ferritic stainless steel RHS and SHS, this section presents the comparison of the combined loading test results with the different available expressions in the literature. Some experimental investigations on austenitic, lean duplex and ferritic stainless steel RHS and SHS by Zhao et al. [5,6,7] and numerical studies on ferritic RHS and SHS by Arrayago et al. [4] can be found in the literature regarding combined loading, besides some approaches for carbon steel cross-sections by Liew and Gardner [21]. The different proposals have been evaluated through a comparison of the experimental ultimate loads with the ultimate capacities predicted by these different approaches.

Additionally to the combined loading test results presented in this paper, the pure compression experimental resistances have also been incorporated to the study, as well as the ultimate flexural capacities of the cross-sections. These values were obtained from the experimental programme reported and analysed in Arrayago and Real [8], where four-point bending tests were performed on several beams with the same cross-sections. Although their analysis is out of the scope of this paper, the key experimental results of these tests are summarized in Table 8 , where $F_{u}$ is the ultimate load, $d_{u}$ is the corresponding midspan deflection and $M_{u}$ is the reached ultimate bending moment. The comparison of the bending moment capacities against 
elastic $\left(\mathrm{M}_{\mathrm{el}}\right)$ and plastic $\left(\mathrm{M}_{\mathrm{pl}}\right)$ bending moment capacities is also presented, and finally, the rotation capacity $R$ is provided for those beams showing a $M_{u} / M_{p 1}$ ratio greater than 1 .

Table 8. Summary of key experimental results for simply supported beams in [8].

\begin{tabular}{ccccccc}
\hline \hline Section & $\begin{array}{c}\mathrm{F}_{\mathrm{u}} \\
{[\mathrm{kN}]}\end{array}$ & $\begin{array}{c}\mathrm{d}_{\mathrm{u}} \\
{[\mathrm{mm}]}\end{array}$ & $\begin{array}{c}\mathrm{M}_{\mathrm{u}} \\
{[\mathrm{kNm}]}\end{array}$ & $\mathrm{M}_{\mathrm{u}} / \mathrm{M}_{\mathrm{el}}$ & $\mathrm{M}_{\mathrm{u}} / \mathrm{M}_{\mathrm{pl}}$ & $\mathrm{R}$ \\
\hline \hline $\mathrm{S} 1$ & 66.1 & 42.4 & 16.9 & 1.18 & 0.96 & -- \\
$\mathrm{S} 2$ & 27.2 & 59.6 & 6.9 & 1.23 & 1.00 & 1.4 \\
\hline $\mathrm{S} 3-\mathrm{Mj}$ & 43.2 & 63.8 & 11.0 & 1.36 & 1.02 & 1.8 \\
$\mathrm{~S} 3-\mathrm{Mi}$ & 26.3 & 104.4 & 6.7 & 1.26 & 1.01 & 2.1 \\
\hline S4-Mj & 64.1 & 16.3 & 16.3 & 1.03 & 0.84 & - \\
S4-Mi & 48.6 & 22.5 & 12.4 & 0.97 & 0.83 & -- \\
\hline S5-Mj & 19.2 & 48.0 & 4.9 & 1.26 & 1.03 & 1.9 \\
S5-Mi & 13.9 & 49.9 & 3.5 & 1.09 & 0.94 & - \\
\hline \hline
\end{tabular}

\subsection{Interaction equation assessment}

The analysis of the expressions gathered in the current version of EN1993-1-4 [2] and those proposed in the literature $[4,5,6,7,21]$ based on the Continuous Strength Method are presented in order to assess the applicability of these equations to ferritic stainless steel RHS and SHS sections subjected to combined axial compression and uniaxial bending moment. Since EN1993-1-4 [2] predicting expressions depend on cross-sectional classification, the crosssectional classification currently coded in [2] and the revised limits proposed by Gardner and Theofanous [18] have been assessed.

Codified expressions for the determination of the bending moment capacity according to EN1993-1-4 [2] depend on section classification and are given by Eqs. (14)-(16):

$$
\begin{array}{ll}
M_{\mathrm{Rd}}=\mathrm{M}_{\mathrm{pl}, \mathrm{Rd}}=\mathrm{W}_{\mathrm{pl}} \cdot \sigma_{0.2} & \text { for Class } 1 \text { or } 2 \text { cross-sections } \\
\mathrm{M}_{\mathrm{Rd}}=\mathrm{M}_{\mathrm{el}, \mathrm{Rd}}=\mathrm{W}_{\mathrm{el}} \cdot \sigma_{0.2} & \text { for Class } 3 \text { cross-sections } \\
\mathrm{M}_{\mathrm{Rd}}=\mathrm{W}_{\mathrm{eff}} \cdot \sigma_{0.2} & \text { for Class } 4 \text { cross-sections }
\end{array}
$$

For cross-sections classified as Class 1 or 2, the plastic bending capacity needs to be considered Eq. (14), for Class 3 sections the elastic bending capacity is determined by Eq. (15), and 
finally, for Class 4 cross-sections, effective properties need to be considered through Eq. (16), where $\mathrm{W}_{\mathrm{pl}}$ is the plastic modulus, $\mathrm{W}_{\mathrm{el}}$ is the elastic modulus and $\mathrm{W}_{\mathrm{eff}}$ is the effective modulus.

Specifications in EN1993-1-4 [2] for the verification of cross-sections subjected to a combination of axial compression and bending moment loading conditions also refer to the corresponding equations for carbon steel in EN1993-1-1 [17]. For axial and bending moment interaction in slender cross-sections, Class 3 and 4, a linear equation is adopted, Eq. (17), assuming that failure occurs when the maximum stress reaches the yield stress. $N_{E d}, M_{y, E d}$ and $M_{z, E d}$ are the applied loads; $N_{R d}$ is the axial compression resistance, $M_{y, R d}$ and $M_{z, R d}$ are the moment resistances about the principal axes, calculated from Eqs. (4)-(5) and (15)-(16), repectively. Concerning stocky cross-sections, Class 1 and 2, some plastic response is allowed and the interaction between axial force and bending moments is governed by Eq. (18), where $\mathrm{M}_{\mathrm{N}, \mathrm{y}}$ and $\mathrm{M}_{\mathrm{N}, \mathrm{z}}$ are the axial-reduced plastic moment resistances about the principal axes, given in Eq. (19) with $n=\mathrm{N}_{\mathrm{Ed}} / \mathrm{N}_{\mathrm{pl}}$.

$$
\begin{aligned}
& \frac{N_{E d}}{N_{R d}}+\frac{M_{y, E d}}{M_{y, R d}}+\frac{M_{z, E d}}{M_{z, R d}} \leq 1.0 \\
& \left(\frac{M_{y, E d}}{M_{N, y, R d}}\right)^{\frac{1.66}{1-1.13 n^{2}}}+\left(\frac{M_{z, E d}}{M_{N, z, R d}}\right)^{\frac{1.66}{1-1.13 n^{2}}} \leq 1.0 \\
& M_{N, R d}=M_{p l, R d} \frac{1-n}{1-0.5 \cdot a_{f}}, \text { where } a_{f}=\frac{A-2 h t}{A} \leq 0.5
\end{aligned}
$$

Expressions for the determination of pure compression and bending in isolation have been widely analysed for the CSM while general loading conditions, such as combinations of axial compression and bending moment, still need to be carefully studied and design proposals are not yet sufficiently contrasted and confirmed.

However, some research on combined loading predictions through CSM has already been published: numerical studies on ferritic stainless steel RHS and SHS by Arrayago et al. [4] and 
experimental results on austenitic, lean duplex and ferritic stainless steel RHS and SHS by Zhao et al. [5,6,7]. The preliminary results reported by the former suggested that the best approach for the determination of the ultimate capacities of RHS and SHS subjected to combined loading consists on considering the interaction expression codified in EN1993-1-4 [2] for Class 1 and 2 cross-sections but considering the fundamental capacities determined according to CSM instead of the plastic ones, as presented in Eqs. (20) and (21). This was also experimentally confirmed for austenitic, lean duplex and ferritic RHS and SHS by Zhao et al. $[5,6,7]$, where a linear interaction formula, with CSM endpoints, was proposed for slenderness higher than $\bar{\lambda}_{\mathrm{p}}=0.6$. The definition of the CSM axial capacity of a cross-section is given by Eq. (11), while the bending capacity can be calculated from Eq. (22).

$$
\begin{aligned}
& \left(\frac{\mathrm{M}_{\mathrm{y}, \mathrm{Ed}}}{\mathrm{M}_{\mathrm{N}, \mathrm{y}, \mathrm{CSM}}}\right)^{\frac{1.66}{1-1.13 \mathrm{n}^{2} \mathrm{CSM}^{2}}}+\left(\frac{\mathrm{M}_{\mathrm{z}, \mathrm{Ed}}}{\mathrm{M}_{\mathrm{N}, \mathrm{z}, \mathrm{CSM}}}\right)^{\frac{1.66}{1-1.13 \mathrm{nSSM}^{2}}} \leq 1.0 \\
& \mathrm{M}_{\mathrm{N}, \mathrm{CSM}}=\mathrm{M}_{\mathrm{CSM}} \frac{1-\mathrm{n}_{\mathrm{CSM}}}{1-0.5 \mathrm{a}_{\mathrm{f}}} \text { with } \mathrm{n}_{\mathrm{CSM}}=\frac{\mathrm{N}_{\mathrm{Ed}}}{\mathrm{N}_{\mathrm{CSM}}} \text { and } \mathrm{a}_{\mathrm{f}}=\frac{\mathrm{A}-2 \mathrm{ht}}{\mathrm{A}} \leq 0.5 \\
& \frac{\mathrm{M}_{\mathrm{CSM}}}{\mathrm{M}_{\mathrm{pl}}}=1+\frac{\mathrm{E}_{\mathrm{sh}}}{\mathrm{E}} \frac{\mathrm{W}_{\mathrm{el}}}{\mathrm{W}_{\mathrm{pl}}}\left(\frac{\varepsilon_{\mathrm{CSM}}}{\varepsilon_{\mathrm{y}}}-1\right)-\left(1-\frac{\mathrm{W}_{\mathrm{el}}}{\mathrm{W}_{\mathrm{pl}}}\right) \cdot\left(\frac{\varepsilon_{\mathrm{CSM}}}{\varepsilon_{\mathrm{y}}}\right)^{-2}
\end{aligned}
$$

where $\mathrm{W}_{\mathrm{el}}$ is the elastic modulus, $\mathrm{W}_{\mathrm{pl}}$ is the plastic modulus, $\mathrm{E}_{\mathrm{sh}}$ is the strain hardening modulus given by Eq. (13) for ferritic stainless steels and E is the Young's modulus.

A recent study on carbon steel cross-sections subjected to combined loading by Liew and Gardner [21] proposed a different interaction expression, given by Eqs. (23) and (24), where the the power parameters for RHS and SHS are $\mathrm{a}_{\mathrm{y}}=\mathrm{a}_{\mathrm{z}}=\mathrm{a}+1.2, \mathrm{~b}_{\mathrm{y}}=\mathrm{b}_{\mathrm{z}}=0.8, \alpha=1.75+\mathrm{W}_{\mathrm{r}}\left(2 \mathrm{n}_{\mathrm{CSM}}{ }^{2}-\right.$ $0.15) \leq 1.7+\mathrm{W}_{\mathrm{r}}$, and $\beta=1.6+\left(3.5-1.5 \mathrm{~W}_{\mathrm{r}}\right) \mathrm{n}_{\mathrm{CSM}}{ }^{2} \leq 3.7-\mathrm{W}_{\mathrm{r}}, \mathrm{a}=\mathrm{A}_{\mathrm{w}} / \mathrm{A}$ is the ratio of the cross-section web area to gross area, $\mathrm{W}_{\mathrm{r}}=\mathrm{W}_{\mathrm{ply}} / \mathrm{W}_{\mathrm{plz}}$ is the ratio of the major to minor axis plastic section moduli and $\mathrm{n}_{\mathrm{CSM}}=\mathrm{N}_{\mathrm{Ed}} / \mathrm{N}_{\mathrm{CSM}}$. However, for $\varepsilon_{\mathrm{csm}} / \varepsilon_{\mathrm{y}}$ ratios lower than 3 or slenderness values 
higher than $\bar{\lambda}_{p}>0.5$, interaction parameters need to be considered equal to unity, which leads into a linear interaction curve.

$$
\begin{aligned}
& \left(\frac{M_{y}}{M_{R, C S M}, y}\right)^{\alpha}+\left(\frac{M_{z}}{M_{R, C S M, z}}\right)^{\beta} \leq 1 \\
& M_{R, C S M, y}=M_{C S M, y}\left(1-n_{C S M}^{a_{y}}\right)^{1 / 6} \text { and } M_{R, C S M, z}=M_{C S M, z}\left(1-n_{C S M}^{a_{z}}\right)^{1 / 6 z}
\end{aligned}
$$

Table 9 presents the assessment of the equations codified in EN1993-1-4 [2] when current cross-sectional limits and the revised limits proposed by Gardner and Theofanous [18] are considered. Additionally, the assessment of the expressions based on the CSM is also presented, where the interaction expression proposed in [21] for carbon steel has been considered, together with the interaction proposal suggested in [4] and [5,6,7] combining both EN1993-1-4 [2] and CSM, where the considered cross-sectional slenderness were also based on $\sigma_{\mathrm{cr}}$ values derived from CUFSM [20].

For each cross-sectional classification, the obtained cross-section Class is presented, and U parameters, by which design interaction curves exceed or fall short of the corresponding test data are provided for every interaction expression. Note that proportional loading has been assumed (constant bending moment to axial compression ratio), and that a value of $U$ greater than unity indicates an unsafe result. These ratios have been calculated according to Eq. (25) and the graphical definition presented in Figure 10.

$$
\mathrm{U}=\mathrm{R}_{\text {pred }} / \mathrm{R}_{\exp }
$$




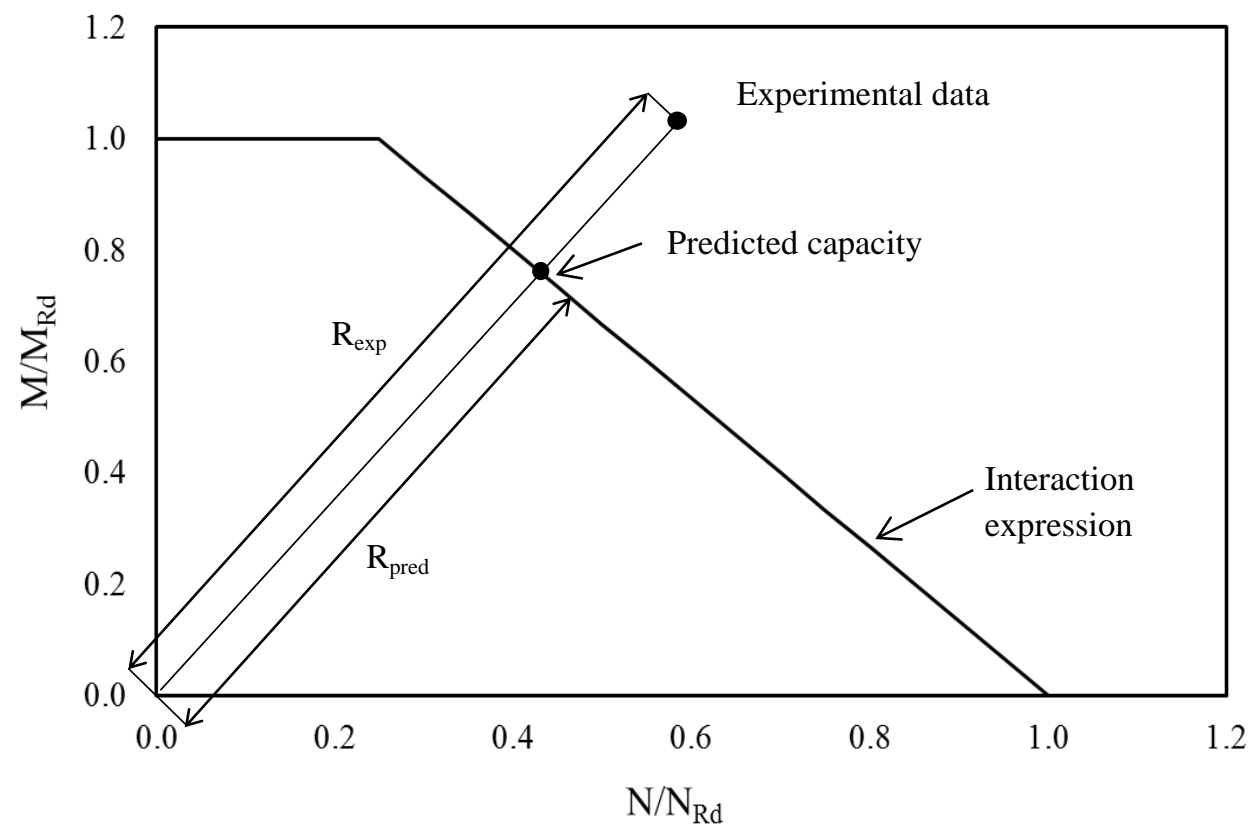

Figure 10. Graphic definition of $U$ parameter for the assessment of design previsions.

Table 9 . Assessment of different interaction expressions for combined loading for the experimental tests.

\begin{tabular}{|c|c|c|c|c|c|c|}
\hline & \multicolumn{4}{|c|}{ EN1993-1-4 [2] } & \multicolumn{2}{|c|}{$\overline{C \text { CSM }}$} \\
\hline & \multicolumn{2}{|c|}{$\begin{array}{c}\text { EN1993-1-4 [2] } \\
\text { classification } \\
\text { Eqs. (17)-(19) }\end{array}$} & \multicolumn{2}{|c|}{$\begin{array}{c}\text { Revised classification } \\
{[18]} \\
\text { Eqs. (17)-(19) }\end{array}$} & \multirow{2}{*}{$\begin{array}{c}\begin{array}{c}{[4-7]} \\
\text { Eqs. }(20)-(22)\end{array} \\
\mathrm{U}\end{array}$} & \multirow{2}{*}{$\begin{array}{c}{[21]} \\
\text { Eqs. (23)-(24) } \\
\mathrm{U}\end{array}$} \\
\hline & Class & $\mathrm{U}$ & Class & $\overline{\mathrm{U}}$ & & \\
\hline S1-CL1 & Class 3 & 0.79 & $\overline{\text { Class } 1}$ & 1.04 & 1.03 & 0.96 \\
\hline S1 - CL2 & Class 3 & 0.77 & Class 1 & 1.02 & 1.02 & 0.94 \\
\hline $\mathrm{S} 2-\mathrm{CL} 1$ & Class 2 & 0.98 & Class 1 & 0.98 & 0.98 & 0.94 \\
\hline $\mathrm{S} 2-\mathrm{CL} 2$ & Class 2 & 0.99 & Class 1 & 0.99 & 0.99 & 0.94 \\
\hline S3-CL1 & Class 1 & 0.98 & Class 1 & 0.98 & 1.02 & 1.00 \\
\hline $\mathrm{S} 3-\mathrm{CL} 2$ & Class 1 & 0.94 & Class 1 & 0.94 & 0.98 & 0.95 \\
\hline $\mathrm{S} 3-\mathrm{CL} 3$ & Class 3 & 0.83 & Class 1 & 1.06 & 1.03 & 0.91 \\
\hline $\mathrm{S} 3-\mathrm{CL} 4$ & Class 3 & 0.80 & Class 1 & 1.03 & 0.99 & 0.87 \\
\hline $\mathrm{S} 4-\mathrm{CL} 1$ & Class 4 & 0.80 & Class 2 & 1.28 & -- & -- \\
\hline $\mathrm{S} 4-\mathrm{CL} 2$ & Class 4 & 0.78 & Class 2 & 1.22 & -- & -- \\
\hline S4 - CL3 & Class 4 & 0.77 & Class 4 & 0.79 & -- & -- \\
\hline S4-CL4 & Class 4 & -- & Class 4 & -- & -- & -- \\
\hline S5 - CL1 & Class 4 & 0.72 & Class 1 & 1.01 & 0.98 & 0.83 \\
\hline S5 - CL2 & Class 4 & 0.74 & Class 1 & 1.03 & 1.00 & 0.86 \\
\hline S5 - CL3 & Class 4 & 0.89 & Class 4 & 0.91 & -- & -- \\
\hline S5 - CL4 & Class 4 & 0.86 & Class 4 & 0.89 & -- & -- \\
\hline Mean & & 0.84 & & 1.01 & 1.00 & 0.92 \\
\hline COV. & & 0.108 & & 0.120 & 0.020 & 0.057 \\
\hline
\end{tabular}

According to the results presented in Table 9, Eqs. (17)-(19) in EN1993-1-4 [2] with the current cross-sectional classification provide quite accurate previsions of the ultimate loads for 
the conducted tests. Nevertheless, when the revised cross-sectional classification is considered, the average ultimate capacity prediction is considerably better, although the classification of several cross-sections, such as $\mathrm{S} 1, \mathrm{~S} 3-\mathrm{Mi}, \mathrm{S} 4-\mathrm{Mj}$ and $\mathrm{S} 5-\mathrm{Mj}$, seems to be too optimistic. Similar results can be observed in Figures 11 and 12 for EN1993-1-4 [2] classification and revised limits, respectively, where the experimental results have been normalized by the axial compression and bending moment resistances calculated according to the corresponding crosssectional classifications and weighted average material properties in Table 2. Interaction expressions codified in EN1993-1-1 [17], Eq. (17)-(19), have also been plotted together with the experimental data. Since Eq. (18) depends on the shape of the cross-sections through the $\mathrm{a}_{\mathrm{f}}$ parameter, as described in Eq. (19), the maximum $\left(\mathrm{a}_{\mathrm{f}}\right.$ or $\left.\mathrm{a}_{\mathrm{w}}=0.5\right)$ and minimum $\left(\mathrm{a}_{\mathrm{f}}\right.$ or $\left.\mathrm{a}_{\mathrm{w}}=0.4\right)$ interaction expressions have been depicted.

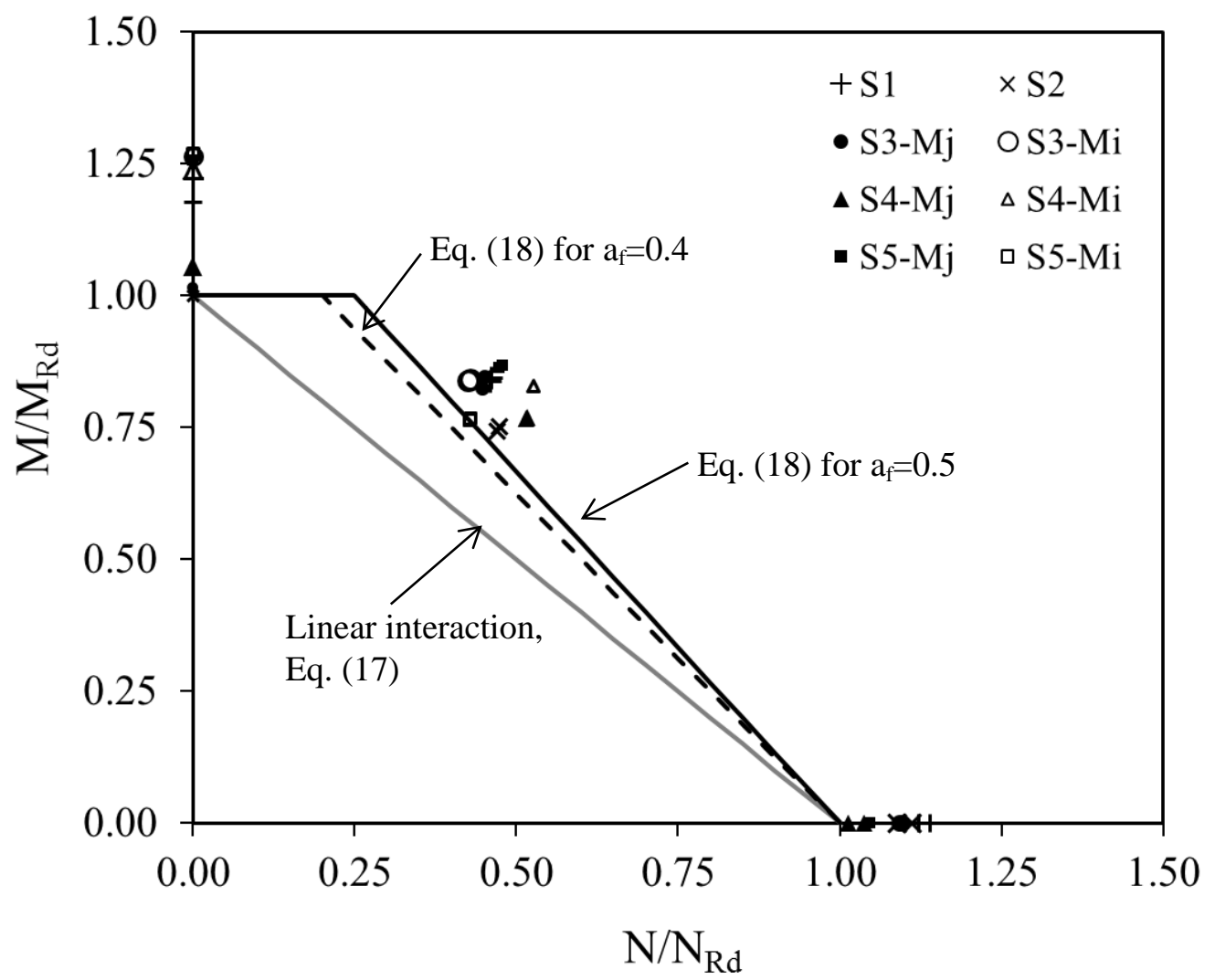

Figure 11. Assessment of Eqs. (17)-(19) for EN1993-1-4 [2] cross-sectional classification for combined loading experimental tests. 


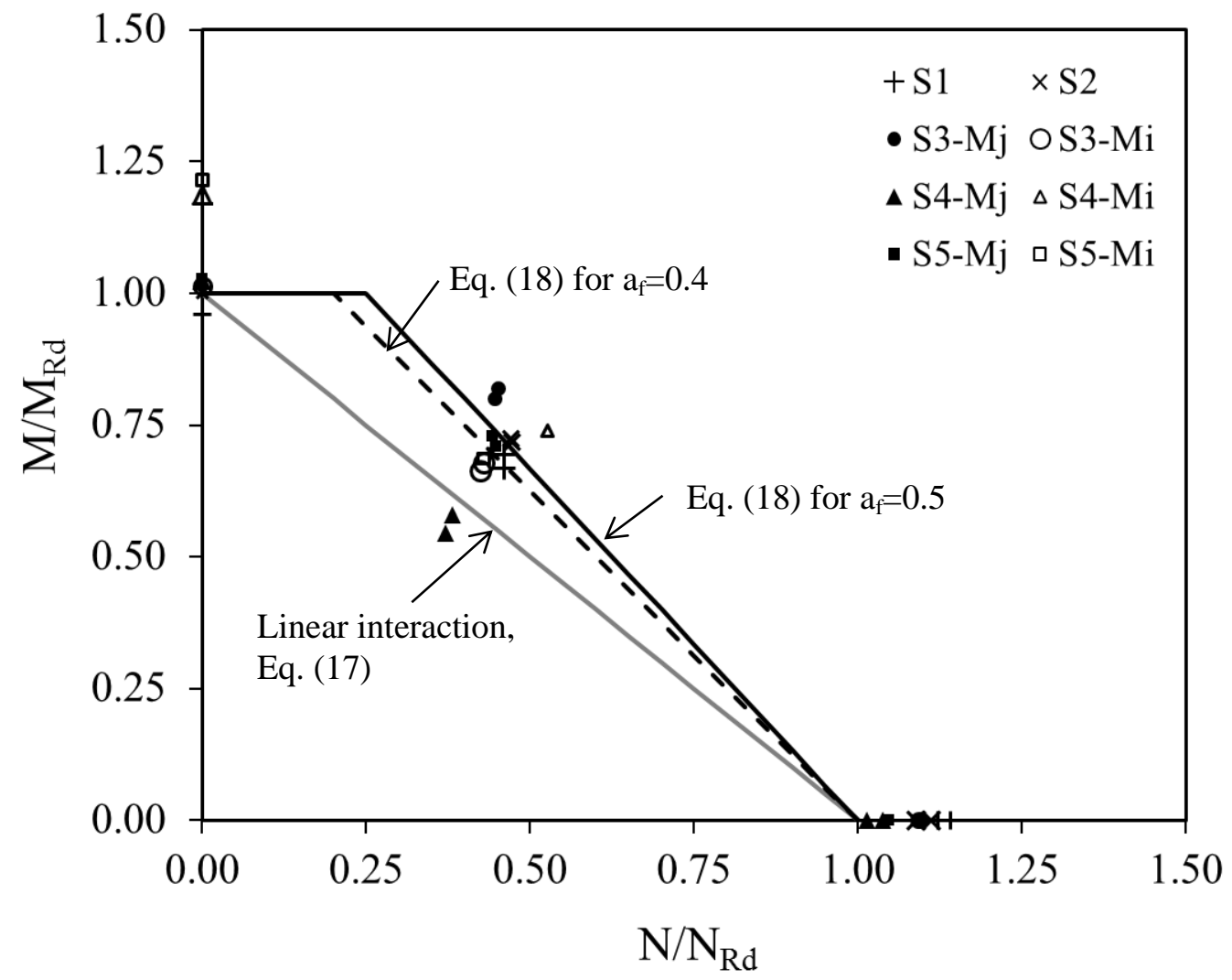

Figure 12. Assessment of Eqs. (17)-(19) for revised cross-sectional classification [18] for combined loading experimental tests.

Besides, the interaction expressions based on the ultimate capacities calculated according to the Continuous Strength Method are assessed in Table 9, Figure 13, where the maximum, minimum and linear interaction expressions have been depicted together with the normalized experimental data and in Figure 14, where the same results are analysed more in detail. S4 and S5-Mi are not analysed as the CSM is not applicable to those cross-sections due to their excessive cross-sectional slenderness. As Table 9 and Figures 13 and 14 show, although the simplified CSM method which considers the CSM fundamental capacities into the interaction expression given in Eq. (20) provides the best ultimate capacity prediction when the mean U ratios are analysed, some unsafe results can be also observed for S1 and S3-Mi specimens. The interaction expression proposed by Liew and Gardner [21] is the one that, keeping results safe, accurately predicts the ultimate resistance of ferritic stainless steel RHS and SHS subjected to combined loading conditions. Nevertheless, the predicted capacities by Eq. (20) are close to 
those obtained experimentally, providing quite good results without introducing any new interaction expression but adopting the equations already codified in EN1993-1-4 [2], and keeping calculations relatively simple for designers, similar to carbon steel design.

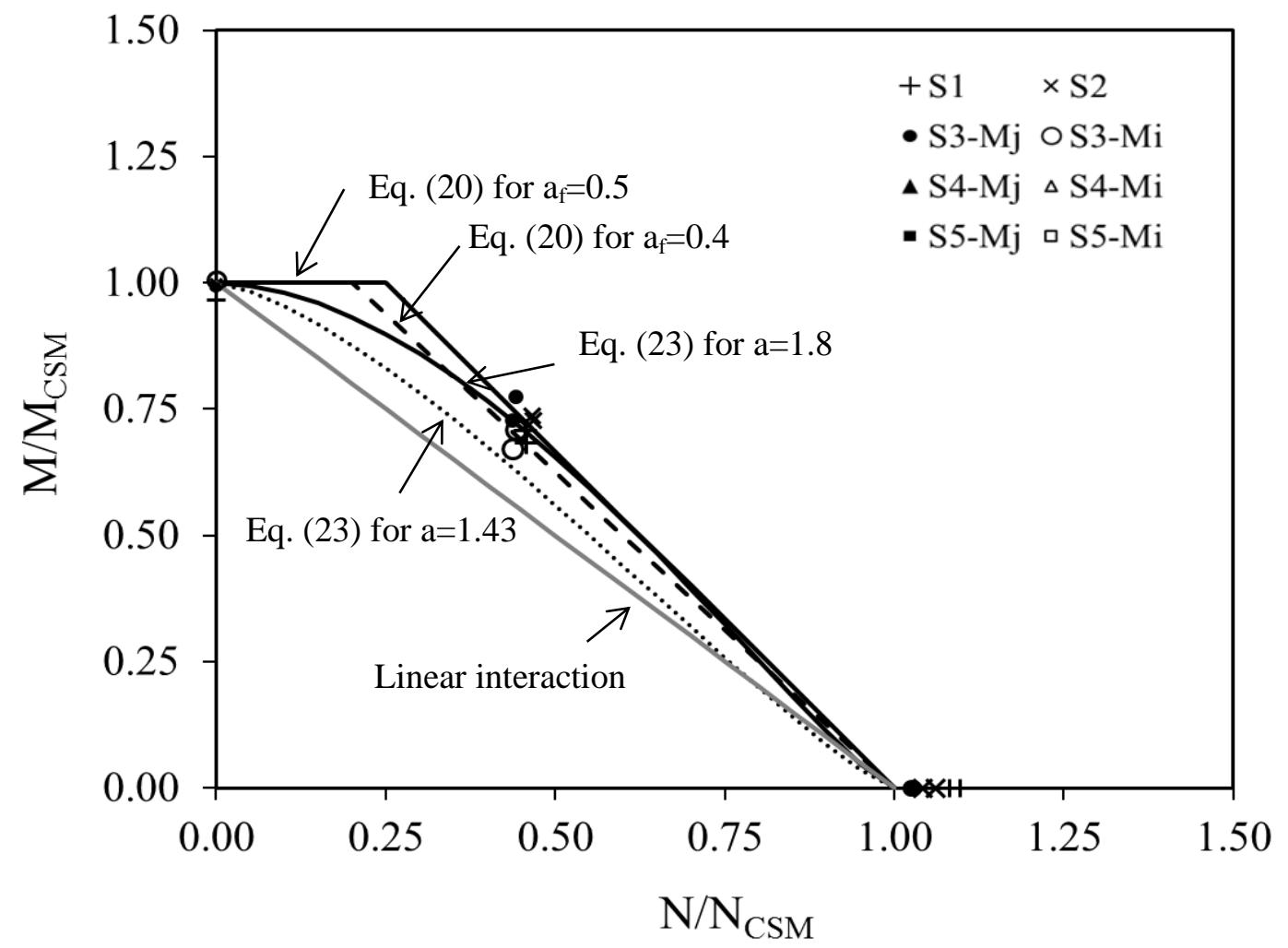

Figure 13. Assessment of Eqs. (20) and (23) for combined loading experimental tests. 


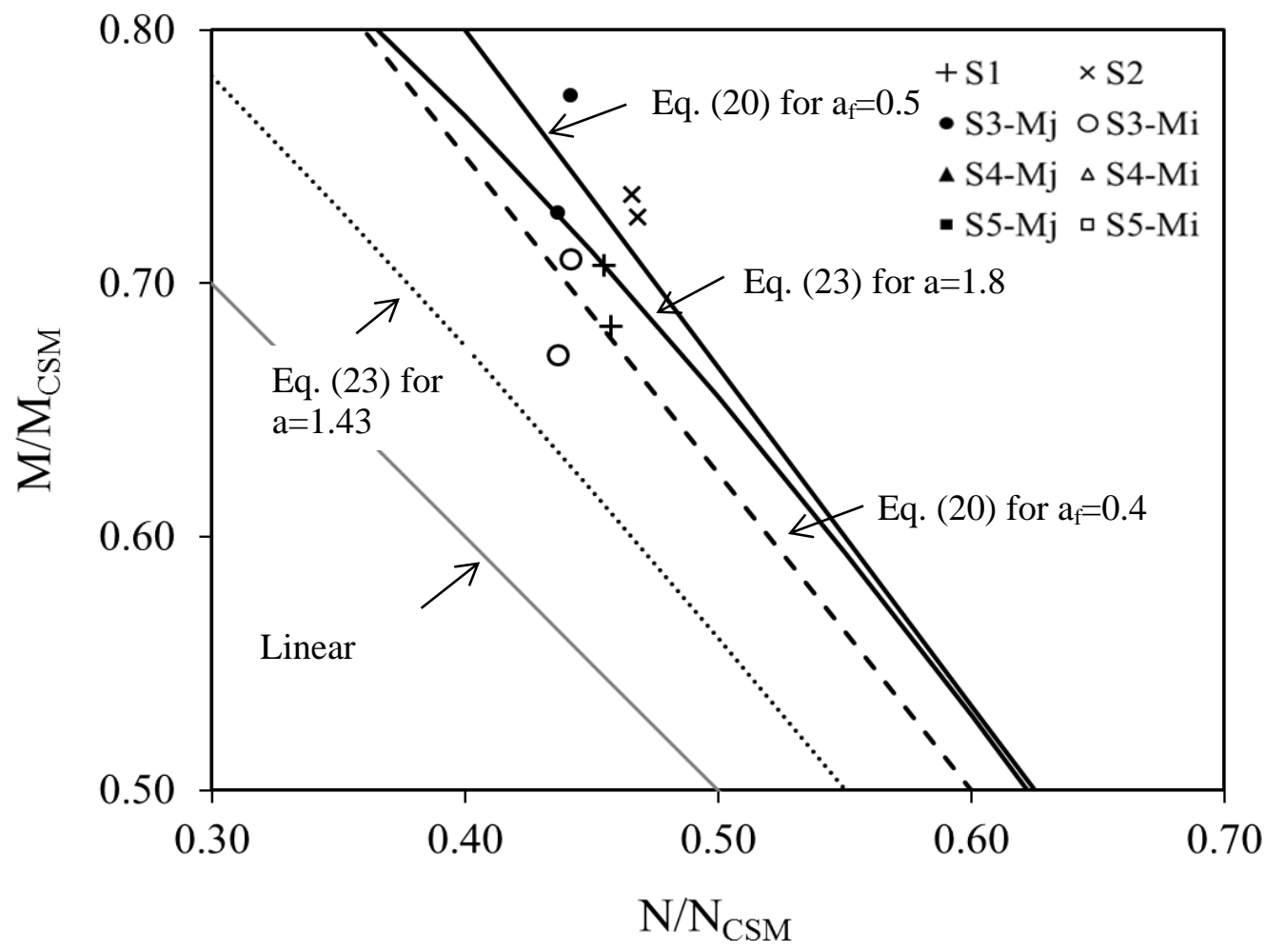

Figure 14. In detail assessment of Eqs. (20) and (23) for combined loading experimental tests.

However, it is important to note that the conclusions derived from the presented experimental results are limited to the $\mathrm{N} / \mathrm{N}_{\mathrm{c}, \mathrm{Rd}}$ ratios close to 0.4 given by the chosen load eccentricities, where the analysed interaction expressions are similar. The assessment of the CSM and simplified CSM interaction expressions for lower $\mathrm{N} / \mathrm{N}_{\mathrm{c}, \mathrm{Rd}}$ ratios would be therefore, still open. Nevertheless, numerical and experimental studies in [4] and [7] for ferritic stainless steels covered $\mathrm{N} / \mathrm{N}_{\mathrm{c}, \mathrm{Rd}}<0.4$ ratios and similar results to those described in this paper were reported.

\section{Conclusions}

This paper presents an experimental study on ferritic stainless steel cold-formed RHS and SHS where five different cross-sections made from ferritic stainless steel grade EN1.4003 were tested under pure compression and combined axial compression and uniaxial bending loading conditions. Tensile tests on flat and corner coupons extracted from the specimens allowed for the mechanical material properties to be determined and have been used in the analysis of the experimental results. 
The pure compression resistance of the analysed cross-sections was determined through ten stub column tests. Experimental results have been used to assess the applicability of the crosssectional classification slenderness limits currently codified in EN1993-1-4 [2] and those proposed in [18] and for determining the most appropriate approach for the prediction of the compression capacity of ferritic RHS and SHS. Test results have demonstrated that although EN1993-1-4 [2] limits for Class 3 are safe, those proposed in [18] seem to provide more accurate Class predictions. Regarding ultimate compression resistance, CSM has been found to provide more accurate prediction that EN1993-1-4 [2] since no discrete classification is considered and strain hardening effects are included.

A total of 16 axial compression and bending moment combined loading tests on ferritic RHS and SHS have also been described in this paper, considering both major and minor bending axis for RHS. Experimental results have been used in the assessment of cross-sectional classification limits [2], [18] showing that cross-sectional classification limits proposed in [18] for bending and compression need to be revised. The different interaction expressions available in the literature [2], [4],[5,6,7] and [21] have been evaluated through these experimental tests. The method proposed in [21] is the one providing safe and accurate predictions, although is a more complex method. On the other hand, the simplified method described in [4]-[5,6,7] provides good results while keeping calculations simple.

All the conclusions highlighted herein are based on limited experimental tests so an extension of the experimental programme should be conducted, where different compression-bending ratios would be considered in order to make conclusions more general. Additionally, a parametric study based on FE simulations and a final statistical validation of the expressions proposed would be also necessary. 


\section{Acknowledgements}

This experimental programme was possible thank to the funding from the Ministerio de Economía y Competitividad (Spain) under the Project BIA 2012-36373. The first author would like to acknowledge the financial support provided by the Secretaria d'Universitats i de Recerca del Departament d'Economia i Coneixement de la Generalitat de Catalunya i del Fons Social Europeu through the FI-DGR 2014 grant. The authors would also like to mention Acerinox for their special support and trust and Tomàs Garcia for his contribution to the experimental investigations.

\section{References}

[1] Cashell KA and Baddoo NR. Ferritic stainless steels in structural applications. Thin-Walled Structures, October 2014, 83, 169-181.

[2] European Committee for Standardization Eurocode 3. Design of steel structures. Part 1-4: General rules. Supplementary rules for stainless steels. Brussels, Belgium; 2006.

[3] Afshan S and Gardner L. The continuous strength method for structural stainless steel design. Thin-Walled Structures 2013, 68, 42-49.

[4] Arrayago I, Bock M and Real E. Preliminary study on the resistance of ferritic stainless steel cross-sections under combined loading. Proceedings of the $7^{\text {th }}$ European Conference on Steel and Composite Structures, Napoli (Italy), September 10-12, 2014.

[5] Zhao O, Rossi B, Gardner L and Young B. Behaviour of structural stainless steel crosssections under combined loading - Part I: Experimental study. Engineering Structures 2015, $89,236-246$ 
[6] Zhao O, Rossi B, Gardner L and Young B. Behaviour of structural stainless steel crosssections under combined loading - Part II: Numerical modelling and design approach. Engineering Structures 2015, 89, 247-259.

[7] Zhao O, Rossi B, Gardner L, Young B. Experimental and numerical studies of ferritic stainless steel tubular cross-sections under combined compression and bending. Journal of Structural Engineering (ASCE), 2015. http://dx.doi.org/10.1061/(ASCE)ST.1943541X.0001366, 04015110.

[8] Arrayago I and Real E. Experimental study on ferritic stainless steel simply supported and continuous beams. Submitted to Journal of Constructional Steel Research

[9] Mirambell E and Real E. On the calculation of deflections in structural stainless steel beams: an experimental and numerical investigation. Journal of Constructional Steel Research, 54(1): 109-133, 2000.

[10] Gardner L and Ashraf M. Structural design for non-linear metallic materials. Eng. Struct. 2006, 28(6), 926-934.

[11] Hradil P and Talja A. Investigating the role of gradual yielding in stainless steel columns and beams by virtual testing. Proceedings of The Fifth International Conference on Structural Engineering, Mechanics and Computation. Cape Town, South Africa, 2013; 1459-1464.

[12] Afshan S and Gardner L. Experimental study of cold-formed ferritic stainless steel hollow sections. Journal of Structural Engineering, 139(5), 2013, 717-728.

[13] Bock M, Arrayago I and Real E. Experiments on cold-formed ferritic stainless steel slender sections. Journal of Constructional Steel Research 2015, 109, 13-23. 
[14] Cruise RB, Gardner L. Strength enhancements induced during cold forming of stainless steel sections. Journal of Constructional Steel Research 2008, 64(11), 1310-1316.

[15] European Committee for Standardization. (2006). EN 1993-1-3. European Committee for Standardization Eurocode 3. Design of steel structures. Part 1-3: General rules. Supplementary rules for cold formed members and sheeting. Brussels, Belgium.

[16] Centre for Advanced Structural Engineering. Compression tests of stainless steel tubular columns. Investigation Rep. S770, 1990. University of Sydney, Australia.

[17] European Committee for Standardization. EN 1993-1-1. European Committee for Standardization Eurocode 3. Design of steel structures. Part 1-1: General rules and rules for buildings. 2005. Brussels, Belgium.

[18] Gardner L and Theofanous M. Discrete and continuous treatment of local buckling in stainless steel elements. Journal of Constructional Steel Research 2008, 64, 1207-1216.

[19] Bock M, Gardner L and Real E. Material and local buckling response of cold-formed ferritic stainless steel sections. Thin-Walled Structures 2015, 89, 131-141.

[20] Schafer B and Ádány S. Buckling analysis of cold-formed steel members using CUFSM: conventional and constrained finite strip methods. In: Proceedings of the $18^{\text {th }}$ International Specialty Conference on Cold-formed Steel Structures 2006, 39-54.

[21] Liew A and Gardner L. Ultimate capacity of structural steel cross-sections under combined loading. Structures 2015, 1, 2-11. 